\title{
An Evaluation of Speed Monitoring Displays for School Travel Safety Improvement
}

David W. Palley

Follow this and additional works at: https://researchrepository.wvu.edu/etd

\section{Recommended Citation}

Palley, David W., "An Evaluation of Speed Monitoring Displays for School Travel Safety Improvement" (2016). Graduate Theses, Dissertations, and Problem Reports. 6371.

https://researchrepository.wvu.edu/etd/6371

This Thesis is protected by copyright and/or related rights. It has been brought to you by the The Research Repository @ WVU with permission from the rights-holder(s). You are free to use this Thesis in any way that is permitted by the copyright and related rights legislation that applies to your use. For other uses you must obtain permission from the rights-holder(s) directly, unless additional rights are indicated by a Creative Commons license in the record and/ or on the work itself. This Thesis has been accepted for inclusion in WVU Graduate Theses, Dissertations, and Problem Reports collection by an authorized administrator of The Research Repository @ WVU. For more information, please contact researchrepository@mail.wvu.edu. 


\title{
An Evaluation of Speed Monitoring Displays for School Travel Safety Improvement
}

\author{
David W. Palley
}

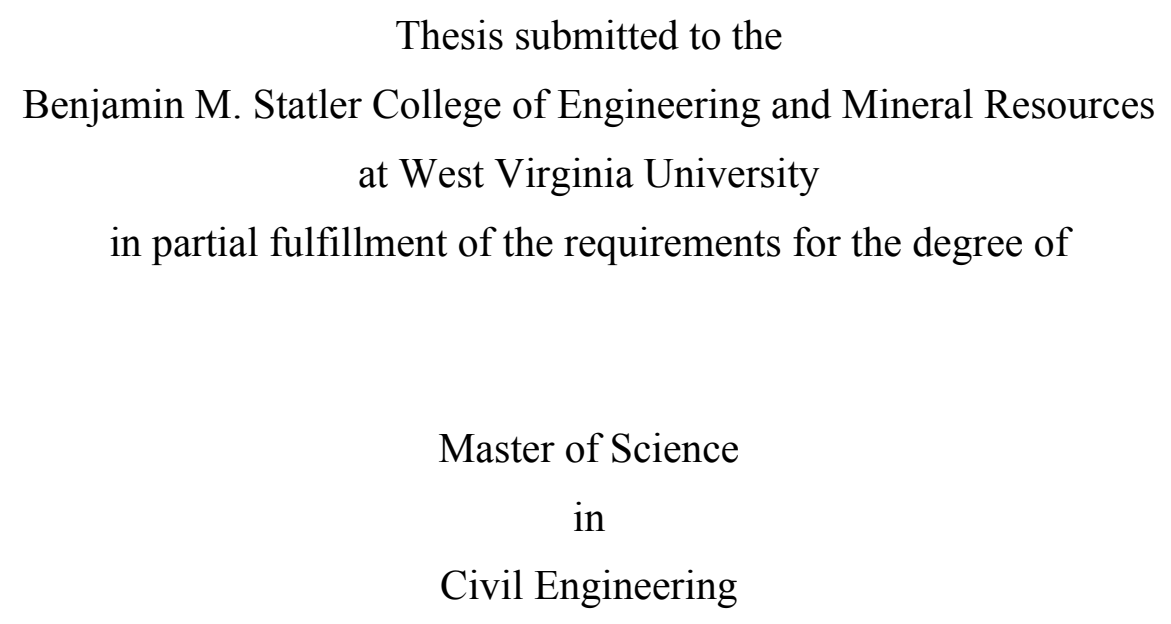

David R. Martinelli, Ph.D.

Avinash Unnikrishnan, Ph.D.

Department of Civil and Environmental Engineering

Morgantown, West Virginia

2016

Keywords: School Zone, School Travel, Safety, Traffic Control, Speed Monitoring Display, Student Survey

Copyright 2016 David W. Palley 


\begin{abstract}
An Evaluation of Speed Monitoring Displays for School Travel Safety Improvement
\end{abstract}

\title{
David W. Palley
}

School travel safety has been a concern for transportation and government officials for a long time. Traffic incidents are among the leading causes of child mortality, and many of these incidents can be related to school travel. While the school travel landscape has changed drastically over the past several decades, little has changed with regards to school zone traffic regulation, particularly in West Virginia. Speed trailers were installed at a rural high school located along a West Virginia highway to assess the effectiveness of these types of devices in lowering vehicle speeds near urban schools along high-speed roads. A student survey was also conducted at three schools to determine school travel mode choice trends and gauge student perceptions of safety in their school travel. While significant reductions in average speeds in the presence of speed trailers were observed, compliance with the school zone speed limit was decidedly low. Student survey responses indicated that attitudes and perceptions of school zone safety varied between types of locations. Under the right circumstances, the implementation of speed monitoring displays can be a valuable measure to reduce school zone speeds, particularly when schools are located on or near high-speed roadways. 


\section{Acknowledgements}

The author humbly thanks the sponsors of this project: the U.S. Department of Transportation, Federal Highway Administration, and the West Virginia Department of Transportation, Division of Highways. A special thanks goes out to Dr. David Martinelli and Dr. Avinash Unnikrishnan for their guidance throughout the development of the project. The author also acknowledges the assistance and guidance of Mr. Donald Williams and Michael Pumphrey of the West Virginia Division of Highways for their advice and assistance in obtaining equipment and evaluating the study site. Thanks also to Dr. Diana Martinelli for her assistance in the development of the survey. 


\section{Table of Contents}

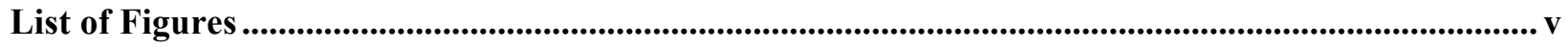

List of Tables................................................................................................................................................................. vi

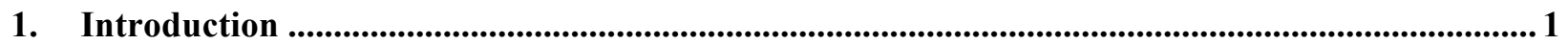

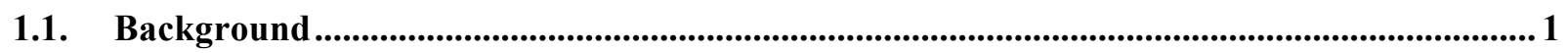

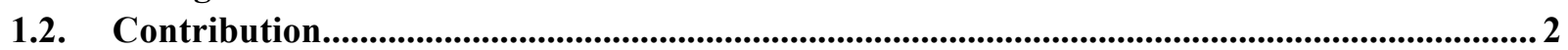

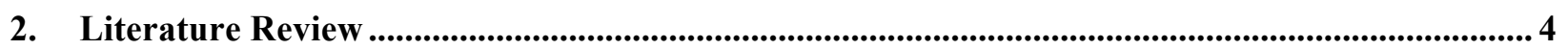

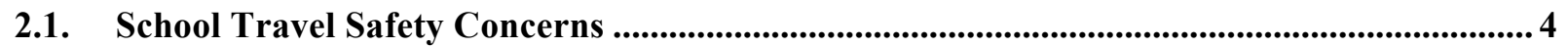

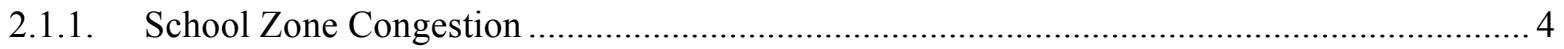

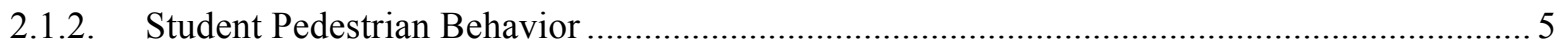

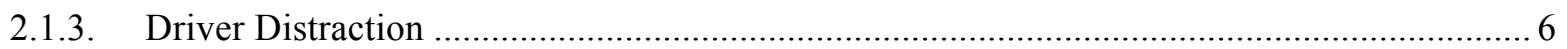

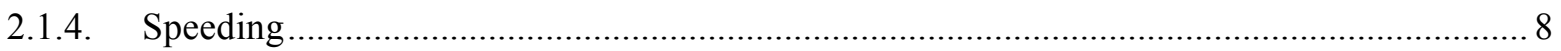

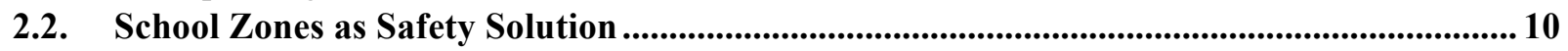

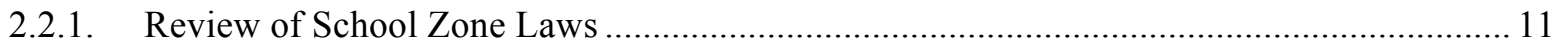

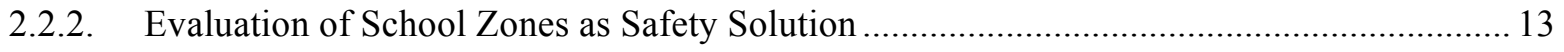

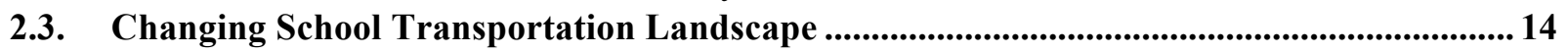

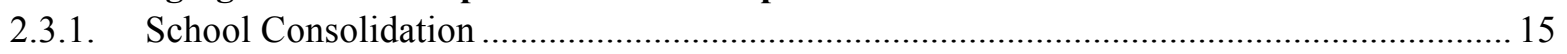

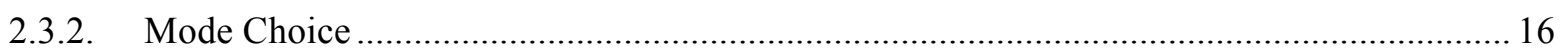

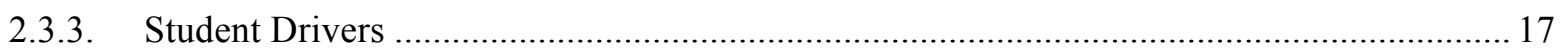

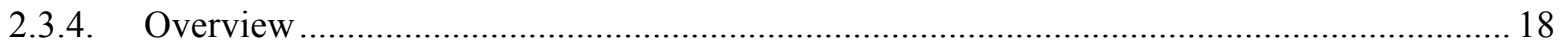

2.4. Possible Measures to Curb Speeding Near Schools .......................................................... 19

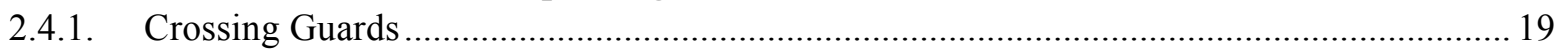

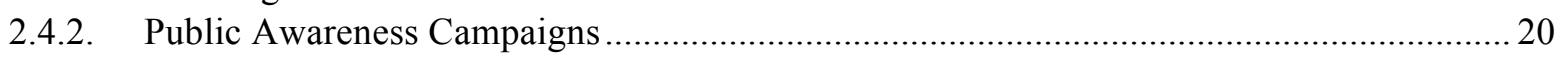

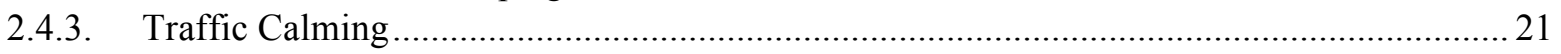

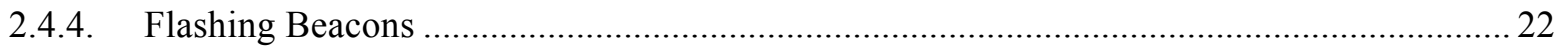

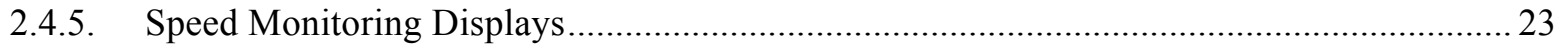

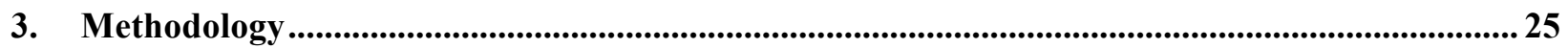

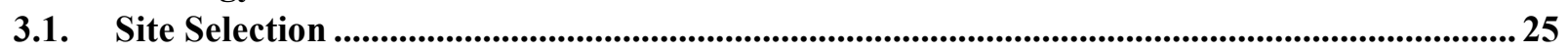

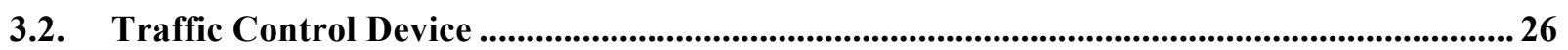

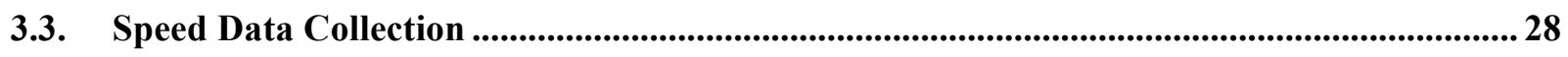

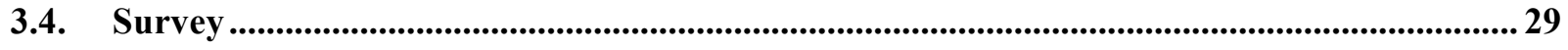

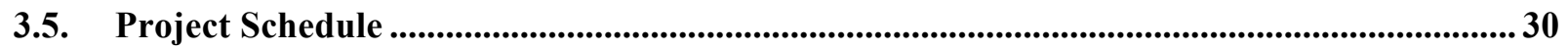

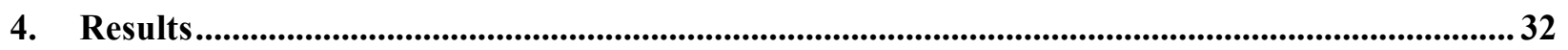

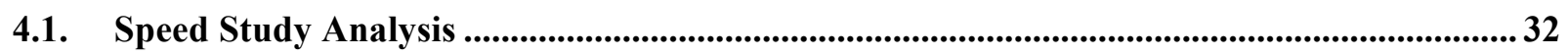

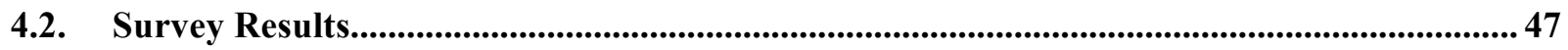

4.3. Summary of Results .............................................................................................................................5 56

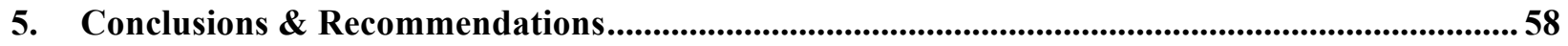

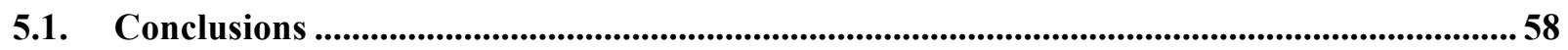

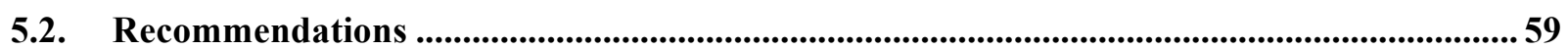

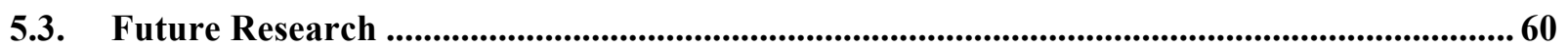




\section{List of Figures}

Figure 2-1: United States School Zone Speed Limits (Hamric et al., 2013)........................................................... 11

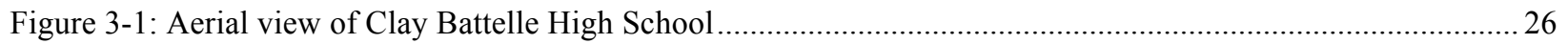

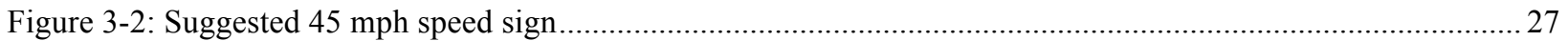

Figure 3-3: Reduced speed 35 mph ahead sign ................................................................................................. 27

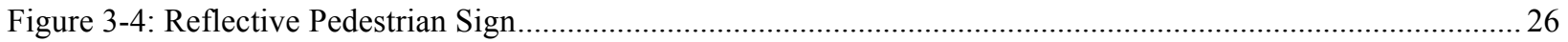

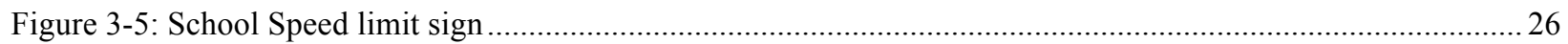

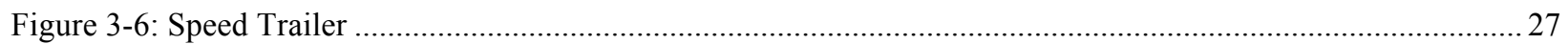

Figure 3-7: Speed Trailer and Speed Tube Locations .............................................................................................28

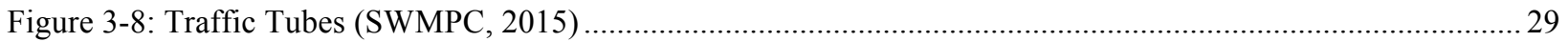

Figure 4-1: Eastbound speeds before trailers empirical density plot and cumulative distribution function .................35

Figure 4-2: Eastbound speeds before trailers normal and lognormal distribution fit comparison ............................. 35

Figure 4-3: Eastbound speeds with westbound trailer empirical density plot and cumulative distribution function .. 36

Figure 4-4: Eastbound speeds with westbound trailer normal and lognormal distribution fit plots .......................... 36

Figure 4-5: Eastbound speeds with both trailers empirical density plot and cumulative distribution function ........... 37

Figure 4-6: Eastbound speeds with both trailers normal and lognormal distribution fit plots ................................... 37

Figure 4-7: Eastbound speeds with eastbound trailer empirical density plot and cumulative distribution function ... 38

Figure 4-8: Eastbound speeds with eastbound trailer normal and lognormal distribution fit plots ............................ 38

Figure 4-9: Westbound speeds before speed trailers empirical density and cumulative distribution plots ................. 39

Figure 4-10: Westbound speeds before speed trailers normal and lognormal distribution fit plots .......................... 39

Figure 4-11: Westbound speeds with westbound speed trailer empirical density and cumulative distribution plots.. 40

Figure 4-12: Westbound speeds with westbound trailer normal and lognormal distribution fit plots......................... 40

Figure 4-13: Westbound speeds after trailer removal empirical density and cumulative density plots...................... 41

Figure 4-14: Westbound speeds after trailer removal normal and lognormal distribution fit plots ............................ 41

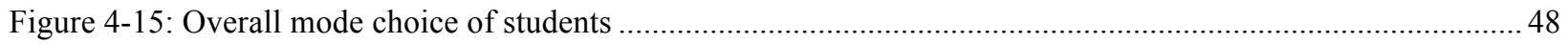

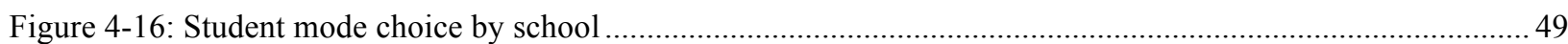

Figure 4-17: Student responses to the statement that distracted driving is a problem in their school zone................51

Figure 4-18: Student agreement with the statement "The speed limit is too slow in my school zone" ......................52

Figure 4-19: Student agreement with the statement "speeding is a problem in my school zone" ............................. 53

Figure 4-20: Student perception of their school zone safety for vehicles ............................................................. 55

Figure 4-21: Student perception of their school zone safety for pedestrians ........................................................ 55

Figure 4-22: Student perception of clarity of traffic signs in and around their school zone..................................... 56 


\section{List of Tables}

Table 3-1: Vehicle Classifications Error! Bookmark not defined.

Table 3-2: Project data collection and survey schedule.

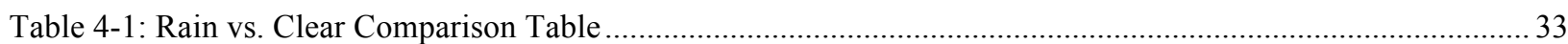

Table 4-2: Eastbound pre-speed trailer speed distribution fit statistics and criteria ......................................... 35

Table 4-3: Eastbound with westbound trailer speed distribution fit statistics and criteria .................................. 36

Table 4-4: Eastbound with both trailers speed distribution fit statistics and criteria ........................................ 37

Table 4-5: Eastbound with eastbound trailer only speed distribution fit statistics and criteria .............................. 38

Table 4-6: Westbound pre-speed trailer speed distribution fit statistics and criteria ........................................ 39

Table 4-7: Westbound with speed trailer speed distribution fit statistics and criteria ....................................... 41

Table 4-8: Westbound post-speed trailer speed distribution fit statistics and criteria ......................................... 41

Table 4-9: Normal distribution fits and probability of speeds being less than $20 \mathrm{mph}$.....................................42

Table 4-10: Westbound Average Speed, Standard Deviation and Percent Compliance .......................................43

Table 4-11: Eastbound Average Speed, Standard Deviation and Percent Compliance ........................................ 43

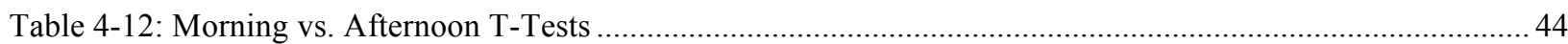

Table 4-13: Before and after speed trailer hypothesis tests of speed reduction .............................................45

Table 4-14: Before and after speed trailer hypothesis test of $2 \mathrm{mph}$ speed reduction ....................................... 46

Table 4-15: Before and after speed trailer hypothesis tests of $5 \mathrm{mph}$ speed reduction...................................... 46

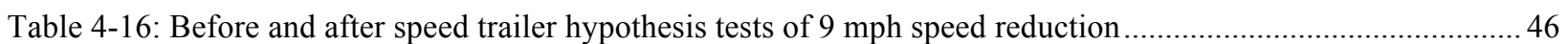

Table 4-17: Before and after speed trailer hypothesis test of 10 mph speed reduction ...................................... 46

Table 4-18: School Zone Speed Limit Student Responses by School ............................................................ 50 


\section{Introduction}

\subsection{Background}

One way or another, millions of children and young adults around the world make their way to school every single school day. Traffic safety near schools has always been a serious concern because of the high concentrations of children present in the areas nearest schools. While child fatality and injury rates related to traffic incidents have been dropping over time, much of this decline may be largely due to decreased rates of walking to school (DiGuiseppi et al.,1997). Despite decades of efforts to make roads surrounding schools safer for children and vehicles, school traffic safety remains a serious concern. A study of crash data in school zones and surrounding areas revealed that crash risk for children was much higher closest to schools, and that crash rates in areas surrounding schools were much higher during school travel times (Warsh 2009). Despite decades of efforts to improve safety in school travel, students occasionally still face dangerous school travel conditions.

Accidents of all types and levels of severity still happen in school zones throughout the world. In 2001 over 500 children ages 15 or younger died on U.S. roads in pedestrian-vehicle crashes and 24,000 were injured, accounting for roughly one third of people involved in such crashes (NHTSA, 2002). Furthermore, roughly 800 children are killed in all types of traffic related accidents during school hours annually, accounting for $14 \%$ of total child roadway fatalities and 152,000 school-aged children are injured in crashes during school hours every year (TRB 2002). A large number of factors contribute to the continued safety concerns related to school travel. Among these factors are congestion, children's pedestrian behavior, driver distraction and speeding. 
When studying travel to and from school, an important distinction should be made between school travel and school zone travel. The two are very much related and largely similar. The difference lies in their breadth and scope. School travel describes any trips, in their entirety, to and from school by any mode of transport. School zone travel, however, only describes the part of those same trips that takes place in the area immediately abutting the school. School zones are prescribed areas defined by legislature at the state or local level. A school zone describes a very specific region, while school travel describes more broadly all travel to and from school. While the term school zone may have different definitions with regards to size, regulation and speed limit, the meaning of school travel remains relatively consistent regardless of location. School zones are certainly a very important part of the overall school travel consideration, but in order to achieve a fuller and more consistent picture of the issues regarding children's safety in school travel, the remaining aspects of trips to school should be considered.

School travel is an important issue that demands the attention of transportation engineering professionals. This research aims to address school travel safety concerns related especially to vehicle speeds in rural schools.

\subsection{Contribution}

While a number of past studies have looked at traffic control for school zone safety improvement, few have explored speed monitoring display use for rural schools along highspeed roads. A study in South Korea, for example, examined speeds before and after speed monitoring display (SMD) installation at an urban school in Gwacheon City. Another study in North Carolina looked at speed reductions in a suburban residential school zone (O'Brien, 2011). Furthermore, these studies do not consider student perceptions of their school travel safety. Their 
primary concern is simply measuring speed changes as a result of the speed monitoring displays. As protecting students is the primary aim of school travel safety measures, student opinions will offer insight into the effectiveness of school zone measures. Also, in high schools, some portion of students are able to drive themselves and may be able to offer insight regarding school travel safety. The objectives of this research are as follows:

(i) Evaluate the effectiveness of speed monitoring displays, and similar traffic control devices which offer drivers feedback on their speeds, for improving school travel safety for rural schools near high-speed roads.

(ii) Examine student perceptions of school travel with regards to their understanding of regulations, and their perceptions of safety.

(iii) Use results to guide school travel regulation and policy. 


\section{Literature Review}

\subsection{School Travel Safety Concerns}

\subsubsection{School Zone Congestion}

As fewer students walk, bike and take the bus to school, traffic operations inevitably become more and more congested during pick-up and drop-off times at the beginning and end of the school day. High concentrations of passenger vehicles congregate at schools and onto surrounding roads during these peak hours, often causing prolonged waits and queues extending out on to roadways adjacent to the school, impacting traffic not normally associated with school travel. Drivers generally consider only the personal effects of choosing to drive their vehicle on a busy route, not the impact that their presence imposes on other travelers. The marginal impacts on congestion of each person choosing to drive add up and can become a serious operational concern. Conditions are different from school to school of course, but in general school congestion has grown as a problem with increases in passenger vehicle use to get to and from school. In some parts of the United States, the number of students using passenger vehicles has increased to about 50\%, up from $12 \% 30$ years ago (Isebrands et al., 2007). This general trend can be observed all over, with parents frequently citing a fear of harm to their children from strangers and from vehicles as reasons to not let their children walk to school (NHTSA, 2004).

Congestion, meaning the overcrowding of roads with vehicles, is an often-overlooked problem when it comes to school travel safety. Increased vehicle presence causes an increased potential for pedestrian-vehicle conflicts at schools and surrounding areas. Pedestrians walking to and from schools are thus at greater risk for collision near congested schools. Even students who get to school in passenger vehicles become pedestrians when leaving their vehicles, so the 
conflicts are not necessarily diminished by a lack of students who walk to and from school. There are several measures that can be taken in attempts to improve safety in congested schools and even reduce congestion problems. Among these are the creation and use of designated dropoff and pick-up locations, separation of transportation modes, traffic calming measures, communication with parents and students about safety expectations and a structured arrival and dismissal period (Isebrands et al., 2007). Traffic control devices can be implemented to try to improve school traffic operations, but some studies have suggested that these devices are frequently improperly installed and ignored outright (Woolridge, 2003). Drivers must be aware of the traffic control device and its purpose for a device to be implemented effectively to improve school safety or alleviate congestion.

The problem of congestion has many influencing factors. Overall, the problem is a function of the trend in mode choice toward personal vehicle use. Many schools were not designed to accommodate the large vehicle volumes that now accumulate at pick-up and drop-off times. In congested school zones, changes should be made carefully in order to improve both efficiency and safety of school traffic operations.

\subsubsection{Student Pedestrian Behavior}

Children account for roughly one third of all people involved in pedestrian-vehicle accidents (NHTSA, 2002). It is generally believed that children account for such a large portion of these accidents because their understanding of road and pedestrian procedures is not as strong as their adult counterparts. Sixty to seventy percent of pedestrian injuries of children under the age of ten are the result of improper crossing behavior (Harborview, 1997). In middle childhood, children develop a level of mobility independence, and a desire to explore. Most parents state that they are comfortable allowing their children to cross neighborhood streets and parking lots 
independently by age 6 or 7 (Wills et al., 1997). However children, especially those aged 5 and 6 , may not yet be cognitively capable of simultaneously handling the several tasks required for safe pedestrian activity (Whitebread \& Neilson, 2000). The task of judging vehicle speeds to find appropriate gaps can be especially difficult for children to accomplish. According to a 2007 study, when waiting to cross, wait times, attention to traffic, missed opportunities, and gap sizes all increase with age. Girls are also more patient when waiting to cross and attend more to oncoming traffic (Barton \& Schwebel, 2007). Addressing children's lacking pedestrian skills can help decrease their chances of being in a pedestrian accident.

Efforts have been made to teach young children how to safely cross streets. A program teaching and demonstrating the proper protocol of waiting, looking both ways, watching for vehicles and continuing to look while walking in the crosswalk in schools shows promise. Baseline understanding and practice of these skills increased from $44 \%$ to $97 \%$ in the school being studied, and was largely maintained and quickly remediated as long as a year after the fact (Yeaton \& Bailey, 1978). Virtual reality simulations have been used in attempts to safely let children practice safe crossing skills. A before-after study of schools using this technology demonstrated that students' real life crossing behaviors were significantly improved after the virtual reality training (McComas et al., 2002). The implementation of programs like the two mentioned above is vital for the continued improvement of school travel safety, but student pedestrian behavior is just one of several important pieces of the puzzle.

\subsubsection{Driver Distraction}

If student behavior is part of the school travel safety problem, then driver behavior should too be considered as an important part of the problem. Driving, despite what many may believe, is an incredibly demanding task. Drivers must be aware of their surroundings, the rules of the 
road, the physical environment surrounding them, and each other to safely navigate even the shortest trip. Driving safely requires continuous focus and attention on the part of the driver. We have built much of our infrastructure and vehicles to be comfortable and easy to drive, however, and driving has become a ubiquitous part of daily live for many of us.

Because the driving environment is so often built for driver comfort, drivers often feel safe enough perform other tasks while driving. Drivers can commonly be found eating, shaving, applying makeup, talking on the phone and texting while driving. With the proliferation of cell phone technology, distracted driving rates have grown at an alarming rate. Distracted driving fatality rates were actually on the decline until 2005 when they suddenly increased $28 \%$. They have since then demonstrated an upward trend (Wilson \& Stimpson, 2010). This increase in distracted driving fatalities has been directly attributed to the coinciding increase in personal cell phone use. While younger drivers more commonly use cell phones while driving, increased risk associated with cell-phone use while driving was demonstrated for both experienced and inexperienced drivers (Klauer et al., 2014).

Many studies have demonstrated drivers' inability to drive effectively while engaging in other tasks. Simply engaging in a hands-free conversation and answering questions while driving led many drivers to spend more time looking directly ahead, looking at the periphery and instruments less frequently or abandoning looking at them entirely (Harblik et al., 2007). In a simulated driving study, phone conversations caused average driving speeds to decrease with an increased variation in speed while drivers reported a higher cognitive workload regardless of conversation difficulty (Rakauskas et al., 2004). In general, even what we may consider minor distractions can have a very noticeable negative impact on driving performance. 
Distracted driving is a serious concern for all personal and commercial vehicle travel, but should receive particular attention in the context of school travel for the same reasons that school travel safety is an important consideration to begin with. The high concentrations of children of all ages traveling to and from schools should motivate a particular caution with traffic safety and operations protocol. Distracted driving in school travel more directly endangers children. A 2009 study of schools across the United States suggests that as much as one out of every six school zone drivers are distracted. The same study showed that drivers were more distracted in the afternoons, and that higher-volume school zones had more distracted drivers (Grabowski \& Goodman, 2009). The already chaotic and often confusing nature of school arrival and dismissal traffic is made even more dangerous for everyone involved when considering the frequency of distracted driving.

Laws prohibiting distracted driving, particularly those related to cell phone use, have become increasingly common. In the U.S., fourteen states have an outright ban on handheld mobile device use while driving. Thirty-eight states and the District of Columbia do not allow novice drivers to use their cell phones while driving, and forty-eight states have banned texting and driving specifically. With regards to school-zone-specific legislature, only Arkansas has banned cell phone use specifically for school zone travel, but that is not considering the states where cell phone use is illegal for all drivers (GHSA, 2016). Much has been done to try to curb distracted driving but, from a legislative policy standpoint, not much attention has been paid specifically to the problem of distracted driving in school travel.

\subsubsection{Speeding}

Vehicle speed is one of the most common and important considerations when looking at school travel safety. Speed is generally defined as exceeding posted speed limits. Roads with 
high vehicle speeds present the greatest risk of collision for pedestrians (Gårder, 2004). Highspeed collisions are also predictably more likely to cause serious injury or be fatal. Higher speeds generally correlate to higher energy impacts resulting in greater damage done. Anderson et al. (1997) suggest that a fatal pedestrian accident is one-sixth as likely to happen if the vehicle's impact speed is $37 \mathrm{~km} / \mathrm{h}(23 \mathrm{mph})$ as opposed to $45 \mathrm{~km} / \mathrm{h}(28 \mathrm{mph})$. This $5 \mathrm{mph}$ reduction in vehicle speeds drastically reduces the fatality of a theorhetical impact with a pedestrian from $60 \%$ to $10 \%$. Higher speeds generally correlate to higher energy impacts resulting in greater damage done. Also, lower travel speeds allow drivers to react and stop more abruptly to pedestrians and other objects along a road. Stopping distance is proportional to the square of vehicle speed (AASHTO, 2011). A small change in vehicle speed can greatly impact a driver's ability to respond to a potential collision, possibly avoiding the collision altogether.

It is for these reasons that school zone laws across the United States and the world generally require reduced speeds near schools, especially when children are present. Despite school zone speed limits being posted, they may not always be obeyed. A lack of compliance with posted school speed limits could happen for a number of reasons. For one, school zone speed limits are often only in effect when children are present. This distinction, while practical from the sense of safety for the children, can be confusing for drivers who regularly traverse these roads. Drivers could be unable to recognize, for example, if children are present at a school. It may be too much to expect every driver to know if children are present in every school zone through which they travel.

Another prospective obstacle to driver compliance with posted school zone speed limits could be lapses in attention. A 2014 study of drivers in school zones demonstrated that when drivers are stopped within a school zone at a traffic light, that their speeds were significantly 
higher after leaving the intersection than the speeds of drivers who traversed the intersection without stopping (Gregory et al., 2014). The study suggests that a lapse in memory occurs, causing drivers who have stopped to forget to travel at school zone speeds. The often unpredictable traffic conditions common nearest schools commonly require drivers to stop, and these distractions may cause a similar lapse in attention, leading to increased speeds.

Harre (2003) also demonstrated that drivers often underestimate their speeds in the presence of children. With no children present, average vehicle speeds were $55.60 \mathrm{kmph}$, with

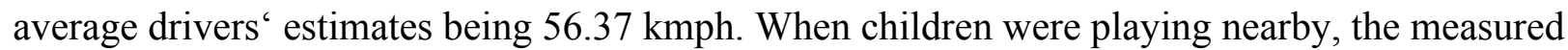
speed was $54.29 \mathrm{kmph}$ and the estimated speed $39.27 \mathrm{kmph}$. When children were waiting to cross the street, measured mean speed was $52.78 \mathrm{kmph}$, and estimated speed $34.02 \mathrm{kmph}$. Drivers understand that they should drive slower in the presence of children, but their actual measured speeds do not reflect the same reduction they report. A variety of prospective methods to curb speeding in school travel are discussed in greater depth in section 2.4.

\subsection{School Zones as Safety Solution}

In response to the aforementioned concerns with school travel safety, measures must be taken to improve safety and prevent or eliminate school-traffic-related injuries and fatalities. The most practical and common means of improving school travel safety is to establish school zones. A school zone broadly describes the roads on school grounds and around that school for which speed limits are reduced. The specific speed limits and reach that define a school zone vary depending on the laws governing the region or state a school is located in. 


\subsubsection{Review of School Zone Laws}

This study will focus on school zone laws within the United States. Within the United States, there are five categories relating to statewide school zone speed limits: $15 \mathrm{mph}, 20 \mathrm{mph}$, 25mph, no speed limit, and multiple speed limits.

\begin{tabular}{|l|l|l|l|l|}
\hline $15 \mathrm{mph}$ & $20 \mathrm{mph}$ & $25 \mathrm{mph}$ & Multiple & None \\
\hline
\end{tabular}

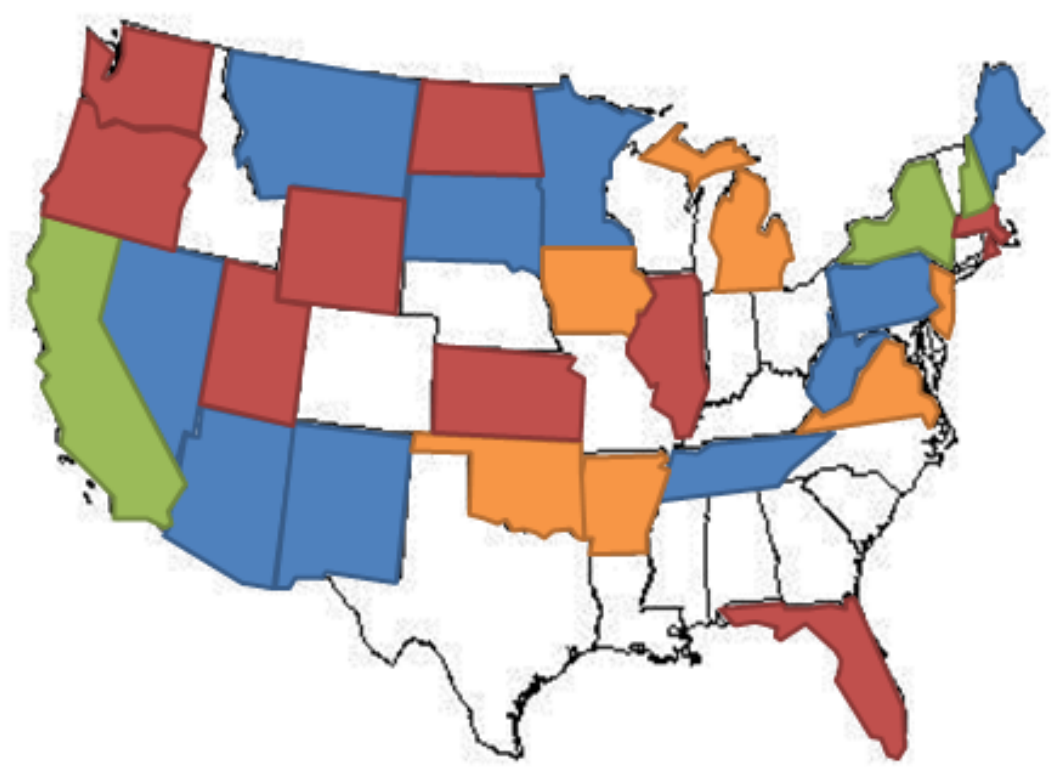

Figure 2-1: State School Zone Speed Limits (Hamric et al., 2013)

As shown in Figure 2-1, twelve states and Washington D.C. have a school zone speed limit of $15 \mathrm{mph}$, the lowest limit in any state. West Virginia is included in these twelve states with a $15 \mathrm{mph}$ school zone speed limit. The West Virginia law states that the speed limit is "Fifteen miles per hour in a school zone during school recess or while children are going to or leaving school during opening or closing hours". It also defines a school zone as "all school property, including school grounds and any street or highway abutting the school grounds and extending one hundred twenty-five feet along the street or highway from the school grounds" 
(West Virginia, 2014). Fourteen states, including Alaska (not pictured above) have a school zone speed limit of $20 \mathrm{mph}$, and 6 states have a $25 \mathrm{mph}$ school zone speed limit. California, New York and New Hampshire all have multiple school zone speed limits allowed by state laws. In the case of California and New York this is likely a function both of state legislative attitudes and of the various types of schools existing there, from urban schools in the middle of large cities to rural schools. Broadly applied traffic laws do not necessarily make sense with such different applications. Finally, there are fifteen states with no designated school zone speed limit, leaving the school zone legislation to local governments and municipalities (Hamric et al., 2013).

The fines for speeding in school zones are often higher than standard speeding tickets. In Texas, for example, while the fines vary from city to city, as does enforcement, additional fines are incurred for speeding in a school zone. A minimum $\$ 25$ court fee is added to school zone speeding tickets, and local fines can be as much as $\$ 325$, usually increasing with the extent of the speeding (Harris County, 2008; Texas, 2012). These fines are meant to deter drivers from speeding through school zones. Speed is an important concern in school zones, but it is only one of the many traffic safety concerns in school zones.

Driver distraction, as previously discussed in section 2.1 .3 , is a pervasive problem and serious safety concern in school zones. Some school zone laws address driver distraction. Arkansas has banned cell phone use for drivers in school zones, for example (GHSA, 2016). While many states such as California, New Mexico and West Virginia ban handheld cell phone use in general, and most states have banned texting and driving, very few states have laws specifically targeting school zone distracted driving. Seventeen states and Washington D.C. have banned cell phone use for bus drivers, with some states specifying that ban to school bus drivers ('Distracted Driving', 2016). It is especially important for school bus drivers to drive safely and 
remain attentive because they transport large numbers of children to and from school. It is also worth noting that while states generally apply these regulations, local governments often further specify school zone laws and regulations. For this reason, it can be difficult to get a clear picture of school zone regulations at the national scale. Every region and every school is unique to some degree, and may warrant specific and distinct rules. On the other hand, inconsistencies cause confusion for drivers, and make it more difficult for them to obey school zone regulations. This confusion could even make school zone traffic less safe for the children who should be protected in school zones.

\subsubsection{Evaluation of School Zones as Safety Solution}

While school zone laws are implemented to improve safety for students and drivers, they may not be effective in achieving this goal. In a series of studies, it was demonstrated that in a small suburban school zone, between $89 \%$ and $94 \%$ of drivers exceeded the posted 20 mph speed limit depending on the time of day (Trinkaus, 1996; Trinkaus, 1998). Such a small percentage of drivers following the speed limit in any school zone is alarming as high speeds so closely relate to fatality rates. This trend, however, is not limited to this one instance. School zone speed limit compliance is generally very poor. A similar study in a different location, for example, found that roughly $50 \%$ of drivers exceeded the school zone speed limit, with $12 \%$ going $15 \mathrm{mph}$ or more above the posted speed limit (Saibel et al., 1999). Vehicle speed directly relates to fatality rates of collisions, and with such a large proportion of drivers speeding $15 \mathrm{mph}$ above the posted limit, the safety of children in such a school zone becomes a serious concern (Anderson et al., 1997). In a 2003 study of driver behavior in school zones, Young et al. concluded that school zone signage had virtually no impact on driver conduct. If drivers are not complying with posted school zone speed limits, then the school zones may not be performing their most important 
function effectively. Eight hundred children are killed in traffic accidents during school hours annually, accounting for $14 \%$ of total child roadway fatalities (TRB 2002). While these tragedies may not all be relatable to speeding, this is usually an important consideration. Transportation design, along with enforcement and education, is the key to stopping these fatalities, and simply establishing a school zone may not be enough alone to change driver behavior near schools.

It is fair to conclude that traditional school zone traffic regulations are a poor deterrent to dangerous driving behavior such as speeding and distracted driving. In a 2006 study by LewisEvans and Charlton, participants, without noticing a change in lane width, slowed their speeds in a driving simulation. Subtle changes in road geometric design can have a noticeable impact on driver behavior. More comprehensive design involving roadway geometry and traffic control devices aimed at targeting driver behavior may be the key to curbing the continued school traffic safety concerns. School travel has changed a good deal in the past several decades, and school zone laws have done little to keep up.

\subsection{Changing School Transportation Landscape}

With traditional school zone laws falling short on reducing driver speeds and improving student safety, the school travel landscape has changed drastically over that last 60 or 70 years. Schools are growing in size and changing locations, students are getting to school in different ways, and driving themselves to school more than they used to. It is essential that school travel safety considerations take these changes into account in order to best address the safety of students in their travels. 


\subsubsection{School Consolidation}

One drastic and important change in our school transportation is the locations of the schools themselves. In 1930, there were 128,000 school districts and over 283,000 schools in the United States. By 1980, however, the number of districts had dropped to 16,000 and the number of schools to 61,000 (DeYound \& Howley, 1990). Small rural schools especially have largely been consolidated into larger, more centrally located schools. This change is driven primarily at the state government level, in attempts to improve the cost effectiveness of schools. Ignoring considerations of the effects of consolidation on the quality of education and community impacts, the consolidation of schools greatly impacts school transport for the clear reason that it changes the trips that students will have to take to get to school.

Corresponding to the drastic school consolidations that took place from 1930 to 1980 , the number of school children taking the bus to school increased from $10 \%$ to roughly $60 \%$. The way students travel to school had to change with their changing school locations. Accordingly, transportation expenditures by public schools increased tenfold over this time as well due to the increased bus ridership, and increased length of many bus routes (Killeen \& Sipple, 2000). A 1975 study by Holland and Barritelle used linear programming and operations research techniques to demonstrate that cost savings by consolidation of rural schools would be limited when considering transportation costs. Beyond the consideration of cost, however, it is important to acknowledge the traffic safety concerns with school consolidation.

Particularly in rural areas, for ease of access, consolidated schools are often located near high-speed highways for ease of access. This is a planning consideration that makes sense when considering the ability of students to get to school, but presents concerns with regards to safety. Drivers already do not comply consistently with imposed school zone speed limits as previously 
discussed. Drastic speed limit differences between highways and school zones could present particular problems in rural school zones that are commonly located near highways as the dramatic changes in speed will be difficult to achieve for drivers. Beyond the concern of speed limit compliance is the underlying safety concerns related to vehicle speeds and collision fatality.

\subsubsection{Mode Choice}

As mentioned above, the consolidation of schools has forced families to change the way their children get to school. In 1969, $47.7 \%$ of United States elementary and middle school children walked or biked to school and only $12.2 \%$ traveled to school in private automobiles (with the remaining $40.1 \%$ taking a bus). By 2009 , only $12.7 \%$ of elementary and middle school children walked or biked to school, while $45.3 \%$ took private automobiles to school (McDonald et al., 2011). This trend is largely associated with, among other things, the consolidation of schools. As schools become more spread out, the average trip length from home to school becomes longer for students, and therefore more difficult to walk or bike. Walking and biking rates are particularly sensitive to travel time. The rates of each drop off sharply with relatively small increases in travel time as demonstrated by multinomial logit models developed using data from Gainesville, Florida (Ewing et al., 2004). Many other studies have shown similar negative relationships between walking or biking likelihood and trip length (Scclossberg et al., 2006; McDonald, 2008; Braza et al., 2004). Distance to school continues to be the primary factor discussed when looking at these trends, but other factors likely play some role in this dramatic shift in mode choice. If both parents work, a student's household has at least one vehicle, or students live in densely populated cities, they are more likely to walk to school (Mcdonald, 2008; McDonald et al., 2011). 
Many parents are unwilling to allow their children to walk to school. The two most common reasons that parents cite are harm to their child from ill-intentioned persons or harm to their child from vehicular traffic (NHTSA, 2004). Safety concerns with school travel also plays an important role in students' mode choice for school travel. If parents do not believe it is safe for their children to walk to school, then they will continue to drive their children or have them take the bus. While this fear of unsafe school travel for pedestrians may be realistic, it proliferates the problem. As fewer students walk or bike to school and more take private vehicles, schools become more congested at pick-up and drop-off times, creating more vehiclepedestrian conflicts and further decreasing the perceived safety for pedestrians around schools. In the pursuit of safer school travel, mode choice is an important piece of the puzzle.

\subsubsection{Student Drivers}

While mode choice for students has shifted away from walking or biking and towards driving, more students have begun to drive themselves to school. In the United States, children can obtain a drivers' license at the age of 16 . High school students start to obtain their licenses and are able to drive themselves to school. This presents specific concerns regarding school travel as teenage drivers often exhibit different driving behavior than their adult counterparts. Psychological and neuroscience research suggests that changes in sensation-seeking and reward sensitive dopamine responses in the teenage brain develop during puberty only begin to find checks as adolescents mature (Steinberg, 2008). Adolescents go through a biological and social developmental change that makes them more likely to take risks. This developmental process can be observed in driving behavior of teenagers. Crash risk for teenage drivers, particularly those sixteen or seventeen years old, is uniformly higher than crash risk for adult drivers (Williams, 2003). Teen drivers are less experienced, and willing to take more risks on the road. 
Although teen fatality rates have dropped, teen driving remains a concern, particularly in school travel. Graduated licensing programs have been used more commonly to ease young drivers into driving. These programs require that student-drivers have more supervised driving experience and thus more driving knowledge when they earn their license. Still, young drivers present a serious concern. In school trips, the highest rate of student injury and fatality occurs when a student is driving a personal vehicle. The injury rates are nearly 5 times higher with a student driver than with an adult driver (2300 and 490 injuries per million trips respectively), and the fatality rates are over 8 times higher with student drivers than with an adult driver (National Research Council, 2002). Teenage drivers have become more common in school travel, and their prevalence in school travel presents a distinct safety concern.

\subsubsection{Overview}

School travel safety will remain a serious concern so long as children continue to be killed and injured going to and from school. The changing school travel landscape has presented a number of new challenges to transportation professionals who hope to improve school travel safety. More students are being driven to school, or driving themselves. Teenage drivers, more common now in our school zones, are likely to take more risks than adults. A 2002 Center for Disease Control report demonstrated that $76.3 \%$ of high school students of driving age drive with some regularity (Shults et al., 2006). Widespread school consolidation has led to longer and less pedestrian friendly routes to school for students nationwide. Schools in rural areas located along or near highways present serious concerns with regards to speeding. A number of measures can and should be taken to target driver behavior in school zones and surrounding roads to improve and maintain safe school travel. Some of these measures are discussed in the following section. 


\subsection{Possible Measures to Curb Speeding Near Schools}

With dated school zone laws, and changing school zone demographics, it is increasingly important to continue to look for ways to improve school traffic safety. Since the implementation of most current school zone laws, it has become much more common for students to drive themselves to school once they receive their driver's license. The growing presence of student drivers raises additional concerns regarding safety. Meanwhile, many modern schools, especially in rural areas, serve students from relatively far away. To be accessible, these schools are often located near highways or other high-speed roads. Such proximity may lead to extreme or unexpected speed limit reductions when approaching school zones. Transportation professionals' goal should be to address these problems and explore options for improving traffic safety in and around schools. Increased driver perception and awareness of safety hazards and problems are essential to improving school zone safety. There are a number of different approaches including but not limited to the use of crossing guards, public awareness campaigns, traffic calming and traffic control devices.

\subsubsection{Crossing Guards}

One possible means of improving school travel safety is the use of crossing guards at intersections and crossings adjacent to or near schools. A crossing guard is traditionally an adult or student who is trained to assist children in safely crossing roads on their way to school. They offer an increased level of security for students walking near schools, but may also have other positive effects on school zone safety. A 2008 study of the Israeli crossing guard programs showed that beyond offering safe crossing to young students, the crossing guard programs left some students with a better understanding of safety and traffic laws (Rosenbloom 2008). The older seventh and sixth grade students who participated in the aforementioned study had a better 
understanding of safety as a result of the presence of crossing guards. While crossing guards are more commonly necessary at elementary schools to help smaller children, the presence of someone to control traffic could help to increase driver awareness and decrease speeds. McCoy and Mohaddes in a 1981 study found that the presence of a crossing guard lowered school zone traffic speeds $3.2-8 \mathrm{~km} / \mathrm{h}$ (about 2-5 $\mathrm{mph}$ ). The study also suggests that the presence of a crossing guard may cause drivers to heighten their awareness, and pay more attention to their surroundings. There is a notable lack of recent research regarding the effects of such crossing guards or traffic directors on driver perception and traffic operations, but the general understanding is that vehicles are more likely to slow down and be attentive in the presence of a crossing guard.

\subsubsection{Public Awareness Campaigns}

A public awareness campaign can also be employed to encourage drivers to be more careful in school zones. Public awareness campaigns are a viable means of informing people about a problem and raising awareness. Public awareness campaigns can range in scope, and accordingly in costs. One advantage of pursuing an awareness campaign is that more than one issue can be targeted. Driver speed is always a concern in school travel, but a public awareness campaign can also aim to reduce congestion (by encouraging carpool and bus use) and increase mindfulness of school zone safety. Because a portion of the targeted audience for a school travel safety public awareness campaign would be high school students who drive themselves to school, it is important to recognize differences in how teenagers respond to public awareness campaigns. Much of the literature on these public awareness campaigns is focused on adolescents because they are more commonly involved in traffic conflicts. A 2001 Norwegian study of adolescent drivers' response to an extensive public awareness campaign was conducted, 
showing a good deal of promise. Perceived risk was increased in respondents and speeding accidents were reduced by $13 \%$ (Ulleburg 2001). A separate study separated high school students into groups based on survey responses, and evaluated the groups' responses to another traffic safety awareness campaign. This study found that the campaigns were less effective in improving safety for certain risk-seeking groups of students, including young males and other risk-seekers (Rundmo 2004). This suggests that while a public awareness campaign is a viable option for improving school zone traffic safety, it may not effectively reach all of its intended audience.

In general, the effectiveness of a public awareness campaign is limited by the public's exposure and willingness to change their behavior. Awareness campaigns target behavior indirectly through various correspondences with a target audience. It is often difficult to measure the effectiveness of an awareness campaign, as demonstrated by an evaluation of San Francisco Bay Area transit awareness campaigns. While implementation was fairly uniform for the various transit security awareness campaigns, using consistent messages and a variety of media to communicate to users, there was no consistent reporting of campaign effectiveness (Rohlich et al., 2010). Beyond the scope of simply making the public aware, further survey or behavioral studies would need to be performed to gauge if a public awareness campaign is reaching its intended audience.

\subsubsection{Traffic Calming}

Traffic calming measures are a common and promising means of reducing vehicle speeds. Traffic calming describes alteration of the geometry of a roadway in an attempt to affect traffic behavior. Traffic calming measures have been shown to reduce road traffic injuries when applied appropriately (Bunn et al., 2003). Traffic calming can be used in school zone traffic 
applications in attempts to improve safety. A study from the Sunaree University of Technology in Thailand looked at the effectiveness of temporary traffic calming devices in reducing school zone speeds. They tested three arrangements and found two to significantly reduce traffic speeds. Vertical alignments of traffic cones down the middle and along both sides of the roadway were effective both with and without flashing lights at the ends of the roadway stretch under consideration (Ratanavaraha, 2013). While these temporary measures would be easy to install and test, long-term solutions to the school travel safety problem are generally preferred. On the other hand, more permanent traffic calming measures would likely have similar effects of traffic safety and are therefore still worth considering. Another concern is that these traffic-calming measures target only traffic speeds, and not driver perception. A 1997 British study by Taylor and Tight discovered that public opinion on traffic calming measures had a significant impact on the success of traffic calming measures. This suggests that further consultation with members of individual communities might help in determining how to best implement traffic calming in their respective school zones. No two schools are the same, and traffic control implementation should be considered specifically in each case.

\subsubsection{Flashing Beacons}

Similar to traffic calming measures, traffic control devices can be installed to help reduce speeds and improve safety. There are a variety of different devices available. Flashing beacons are flashing lights that can be used to draw attention to signs. They are often used in scheduledependent locations such as school zones, to draw attention to the sign when the listed rules are in effect. They can be programmed to flash while the rules described on a sign are in effect. School zones are a popular application of these beacons because their lower speed limits are often only in effect for specific times of the day. Flashing beacons can draw drivers' attention to 
the sign when it is most important. A 2007 study in Illinois found that a rectangular rapidflashing beacon (RRFB) placed at a reduced-speed curve decreased the number of vehicles traveling 6mph above the speed limit. Mean vehicle speed was also reduced (Wilder, 2011). While RRFB are a specific type of beacon, their purpose is to draw drivers' attention much like a traditional flashing beacon. There is a measureable speed decrease and safety increase associated with the implementation of flashing beacons. Drivers do seem to respond to their implementation in certain contexts, but not all circumstances have the same results. Schrader's 1999 study of a variety of traffic control devices in school zones did not show a statistically significant speed reduction caused by mounted flashing beacons. This presents some concerns with the flashing beacons. While they are relatively affordable and easy to install, they are not uniformly effective. This does not mean that they cannot be effectively employed, but their implementation should be executed carefully and under the proper circumstances.

\subsubsection{Speed Monitoring Displays}

Speed monitoring displays (SMDs) are another form of traffic control device that show promise for application near schools. SMDs are speed limit signs that display real-time speeds to drivers, providing instant feedback. A 2003 study by Harre et al. showed that driver perception of speeds around children does not represent actual vehicle speed. Drivers' average reported vehicle speed in the presence of children was as much as $11 \mathrm{mph}$ slower than the actual mean speed measured. This suggests that drivers know they are supposed to slow down in the presence of children, but overestimate how much they actually slow down. A speed monitoring display in a school zone can help alert drivers to their actual speeds and help to close this gap. Multiple recent studies show that SMDs are effective in reducing vehicle speeds. A South Korean study of SMDs showed about a $5 \mathrm{mph}$ reduction in speed and a $6 \mathrm{mph}$ decrease in the $85^{\text {th }}$ percentile 
speed as a result of a speed monitoring display (Lee et al., 2006). Similar speed reductions were still observed as much as a year after the initial installation. A similar North Carolina study also showed a 3 to $4.5 \mathrm{mph}$ decrease in speeds as a result of the installation of speed monitoring displays in school zones (O'Brien, 2011). The speed reductions observed in each of these studies were largely maintained for long periods of time after the installation, suggesting that while drivers may become accustomed to the traffic control, their behavior is still impacted by the presence of SMDs. The sustained success of speed monitoring displays in curbing speeding makes them a particularly attractive option for traffic control in and around schools. 


\section{Methodology}

Given the school travel concerns explored in the literature review, this research aims to address school travel safety concerns related specifically to speeding in rural school zones along or near high-speed roadways. Because so much of West Virginia is rural, these types of school setting are particularly common. A representative school site was selected for examination and tested for traffic control assessment. A traffic control device was selected for testing to evaluate the device's effectiveness in controlling speeding using collected speed data. Furthermore, in order attempt to capture a sense of student attitudes and behavior regarding school travel, a survey was developed and distributed to students in multiple West Virginia high schools.

\subsection{Site Selection}

In selecting a school for the speed study, several factors were taken into consideration. Because rural schools along or adjacent to high speed highways or arterials are common, and the West Virginia school zone speed limit is a uniform $15 \mathrm{mph}$ while children are present, a school near fast moving traffic was sought out to represent this potentially unsafe set of circumstances. Another factor influencing the selection of the school was its proximity to the researchers in Morgantown, West Virginia. While this concern was secondary, the ability to visit and observe the school travel operations was considered helpful in the execution of the project. Another desire was to choose a high school in order to capture, in some capacity, the effects of student drivers on school travel.

From the nearby high schools, one particularly strong candidate was evident. Clay Battelle High School in Blacksville, West Virginia meets all of the aforementioned criteria. It is located directly along Route 7, otherwise known as the Mason Dixon Highway. The aerial view of the school is shown below in Figure 3-1. 


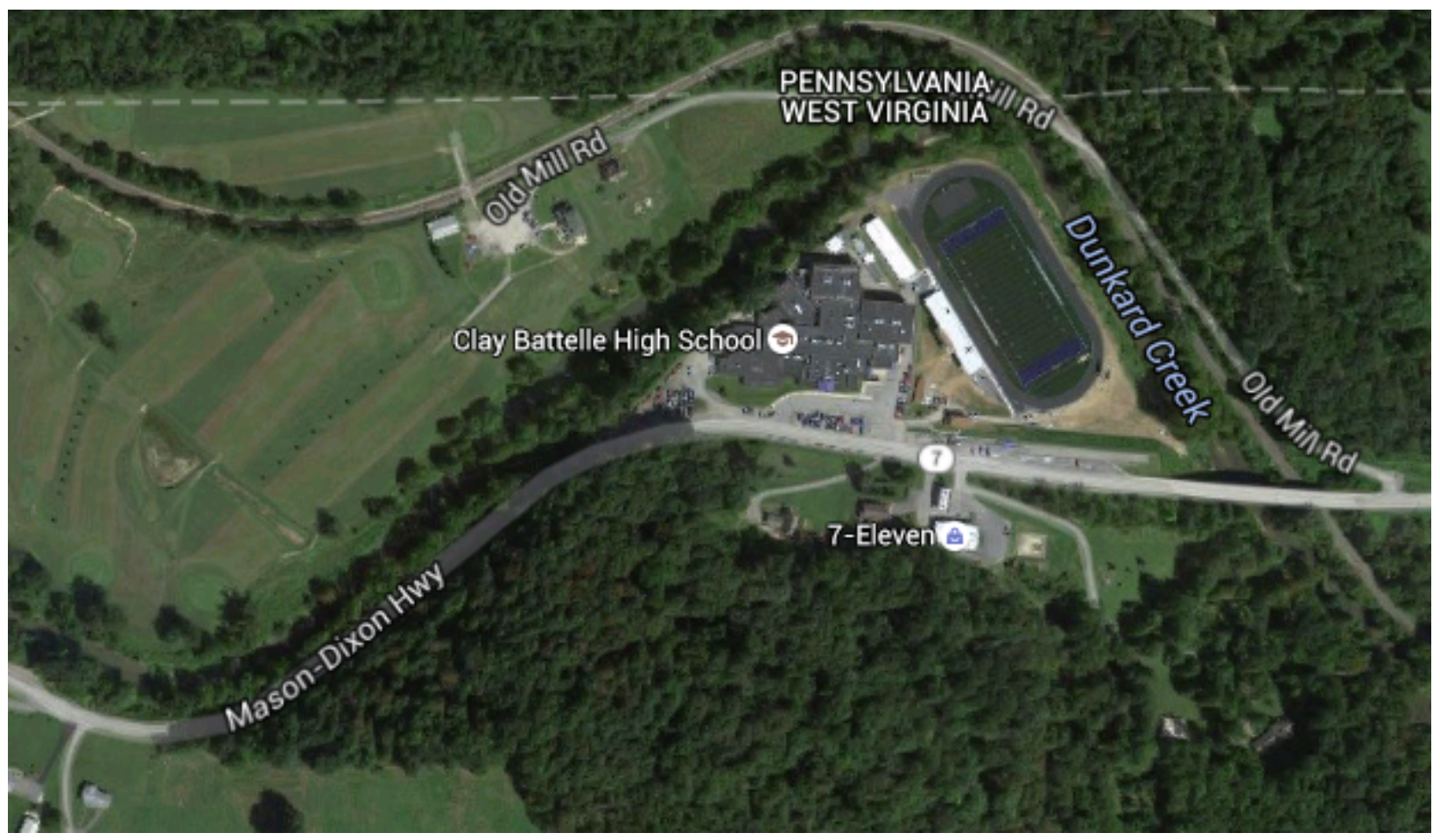

Figure 3-1: Aerial view of Clay Battelle High School

The geometry of the approaches is important to consider. WV-7 is a two-lane highways, with one lane of traffic in each direction. The westbound approach is a relatively straight stretch of road leading toward the school while the eastbound approach has two reversing curves immediately before and leading in to the school zone. The two concerns related to the geometry are the speeds and sight distance. For curved eastbound approach, drivers are not able to see the speed trailers from as far ahead. The curves may also act as a form of traffic calming, forcing drivers to slow down before they are even able to see the speed trailer. The westbound approach does not have the sight distance limitation, so drivers see the speed trailers well before they enter the school zone. The straightaway, however, may lend itself to higher entry speeds.

Speed limits along Route 7 range from $55 \mathrm{mph}$ to $35 \mathrm{mph}$. The stretches to the immediate east and west of the school have a posted speed limit of $35 \mathrm{mph}$. The signage, though consistent with the Manual on Uniform Traffic Control Devices (MUTCD), reflects the often 
changing speed limits and suggested speeds along Route 7. On the eastbound approach, with reversing curves just before the school, there is a curve warning sign with a speed plaque suggesting a speed of $45 \mathrm{mph}$ (Figure 3-2) around the curve succeeded less than 100 feet down the road by a regulatory sign reading "Reduced Speed 35 Ahead" (Figure 3-3).

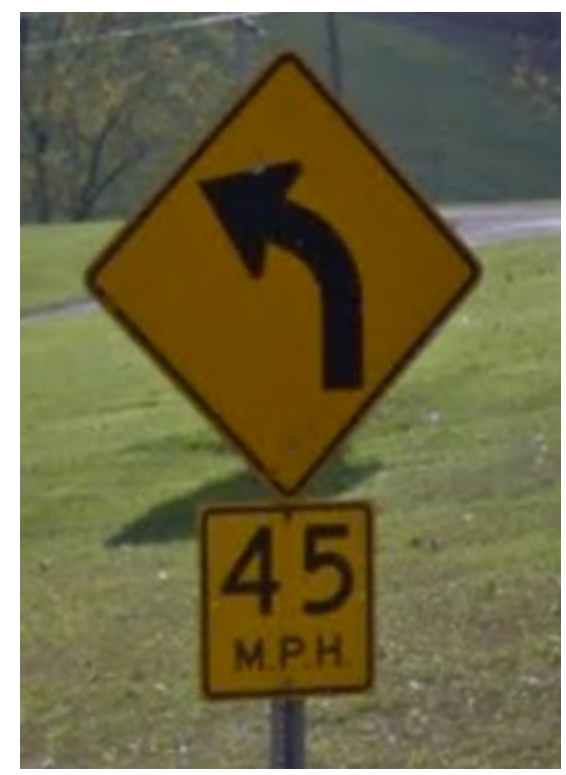

Figure 3-2: Suggested $45 \mathrm{mph}$ speed sign

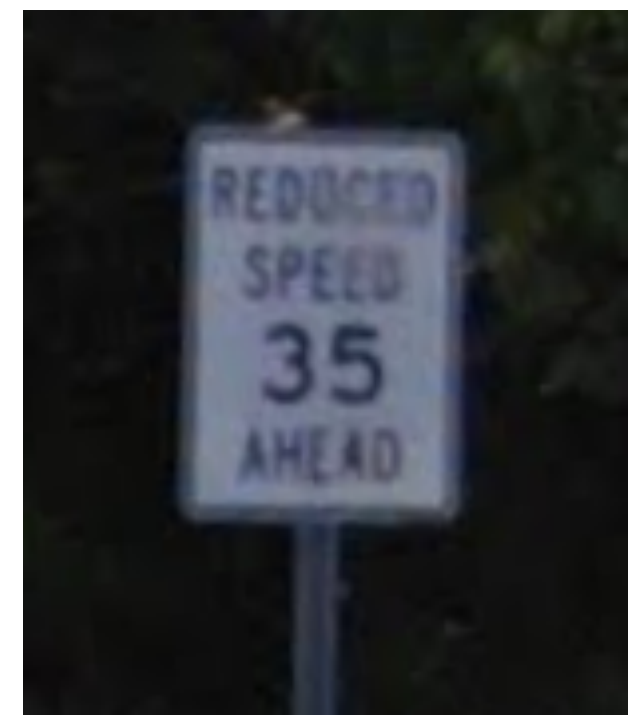

Figure 3-3: Reduced speed $35 \mathrm{mph}$ ahead sign

Both approaches then have a fully retroreflective pedestrian sign as shown in Figure 3-4 roughly 100 feet preceding the partially reflective "School Speed 15 when children are present" signs as shown in Figure 3-5. These signs, as dictated by the MUTCD, are located roughly 125 feet from the school along the road. 


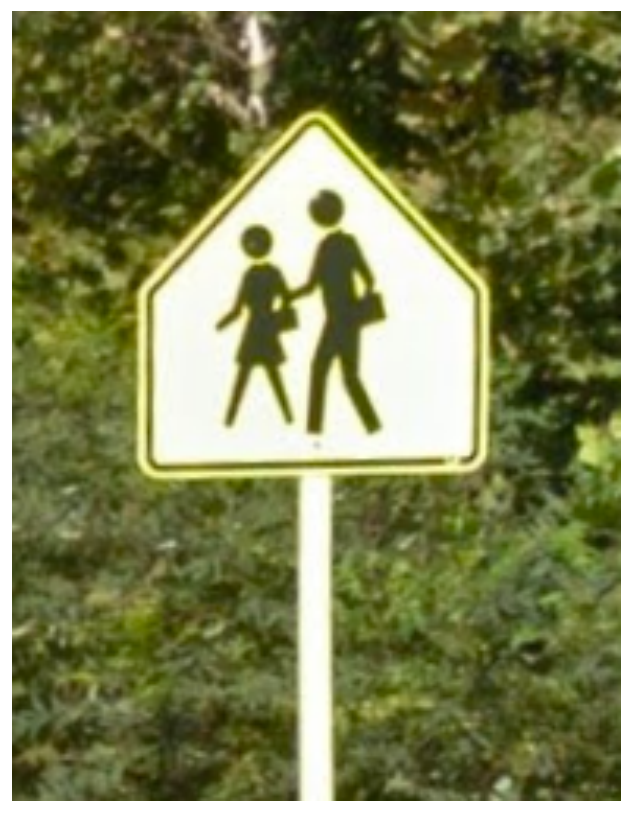

Figure 3-4: Reflective Pedestrian Sign

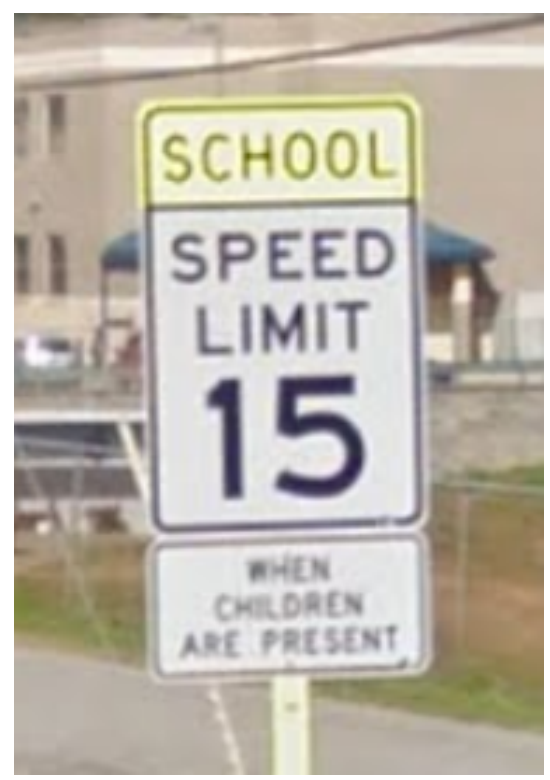

Figure 3-5: School Speed limit sign

Again, speed limits upstream and downstream from the school are as high as $55 \mathrm{mph}$.

There are so many different signs with different speed limits and advisory speeds scattered along WV-7 that not all drivers could be expected to be aware of the posted limits on either side of the school.

\subsection{Traffic Control Device}

After reviewing literature, it was determined that speed monitoring displays would be most useful for reducing speeds through this type of school zone. By giving drivers immediate feedback, speed monitoring displays have been successful in reducing vehicle speeds in other school zones. Their sustained success in reducing rates of speeding as compared to other traffic control devices also sets them apart. Due to the temporary nature of this project, and availability of equipment in West Virginia, it was determined that speed trailers were an acceptable alternative to traditional speed monitoring displays. Speed trailers are commonly used in construction projects to curb vehicle speeding. They are similar to SMDs because they display 
real-time speeds to drivers, and provide feedback. Their advantage here is that they are easily transported, installed and removed. While traditional practice of SMD installation is more permanent, this study is meant to test the effectiveness of these devices without permanently altering the school zone.

Two speed trailers, like the one pictured below in Figure 3-6 were installed at the site: one on the westbound approach and one on the eastbound approach to school. The signs were placed roughly 125 feet from the central school entrance, near the existing school zone speed limit signs. Their speed limit signs were set to match the $15 \mathrm{mph}$ school zone speed limit. The displayed speeds on both signs were set to flash at drivers traveling more than $10 \mathrm{mph}$ above the speed limit (speeds $\geq 25 \mathrm{mph}$ ). In order to capture the potential effects of a speed trailer on opposing traffic flow, the westbound-facing trailer was installed roughly two weeks before the installation of the eastbound-facing trailer.

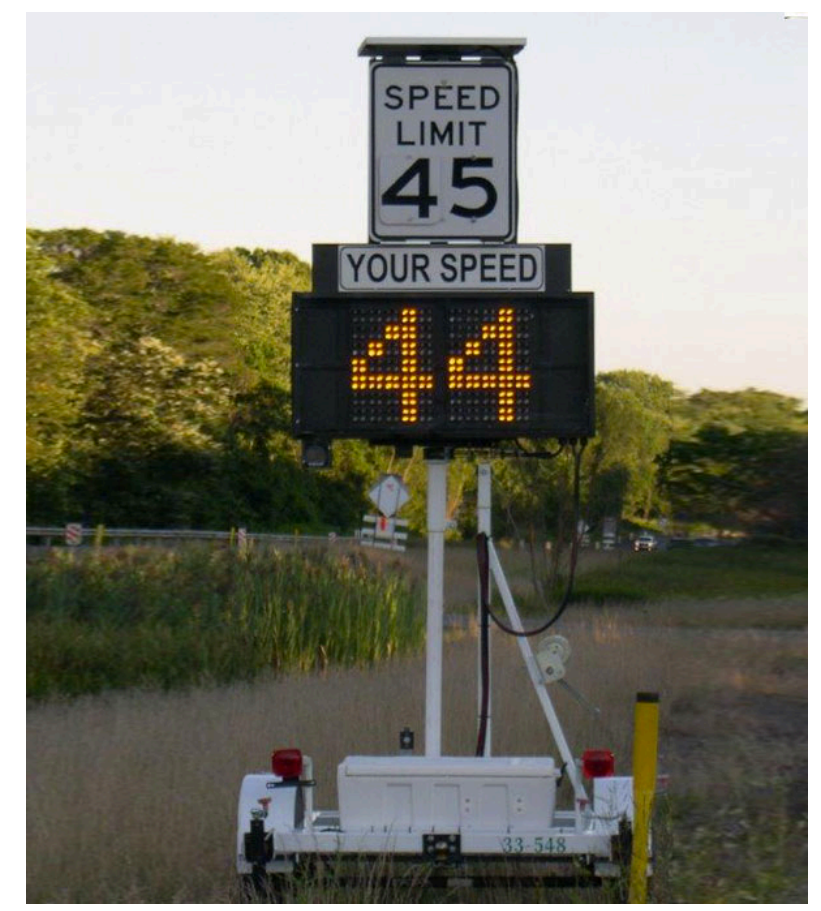

Figure 3-6: Speed Trailer 


\subsection{Speed Data Collection}

To collect vehicle speeds, speed tubes were installed near the westbound-facing speed trailer as shown in Figure 3-7. The tubes were located here for several reasons. Firstly, this location avoids the slowed traffic entering and exiting the school or the businesses across the street from the school. Also, the tubes need to be set in a location were they will not be parked on. Near the middle of the school zone, vehicles frequently park along the side of the road, and that would present potential problems. Furthermore, the box that records the counts needs to be in a secure location, free from pedestrian interference. Because the tubes can measure directionality, the chosen location allow the observation of westbound speeds entering the school zone as well as eastbound speeds exiting the school zone. These different conditions could offer insight into whether any potential speed reductions caused by the speed trailers are maintained throughout the school zone.

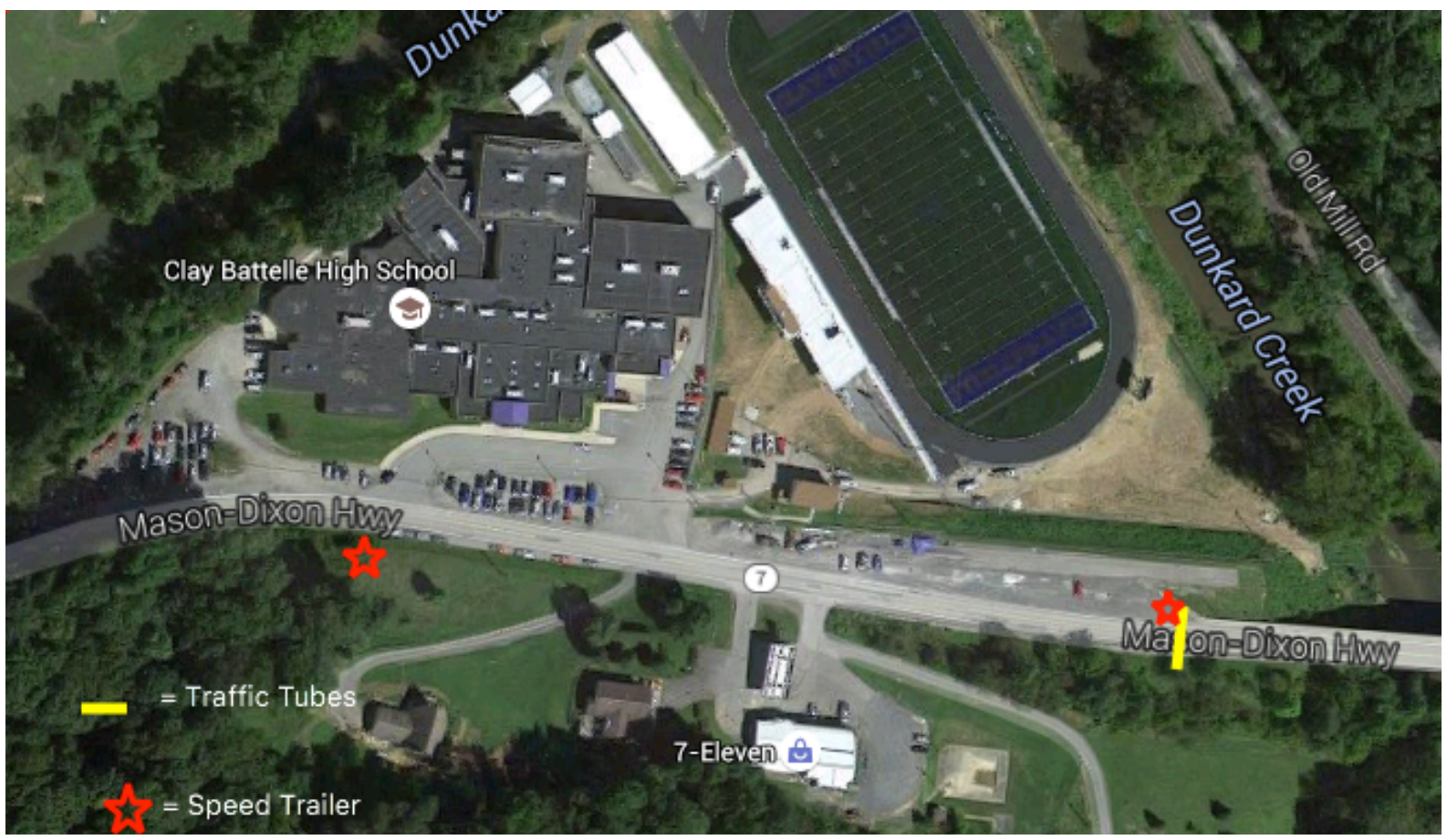


In an arrangement similar to that shown in Figure 3-8, two tubes were placed at a set distance from each other and perpendicular to the flow of traffic. The tubes are connected to a computer that records the order in which the tubes are triggered and the time between each tube triggering.

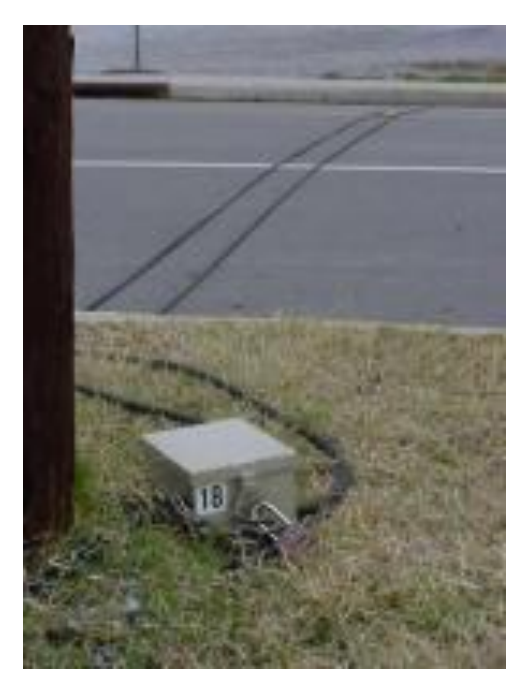

Figure 3-8: Traffic Tubes (SWMPC, 2015)

\subsection{Survey}

The project also included a survey of West Virginia high school students. High school students were surveyed because they include children and young adults who use all modes of transportation for school travel, including driving themselves. Using the list of concerns discovered in the literature review, and especially considering problems related specifically to rural school zones, a list of questions was created and refined. In an attempt to avoid losing students' interest and attention, the survey was designed to be short and simple. The survey was limited to only 14 questions. All of the questions were multiple-choice, with the majority being Likert Scale responses (1 through 7 responses indicating level of agreement to a statement). The survey questions, shown in Appendix A, aimed to capture information about student mode choice for school travel, school travel attitudes and school travel behavior. 
The survey was distributed at three high schools in the Monongalia County School District: Morgantown High School, University High School and Clay Battelle High School. Of the schools surveyed, Clay Battelle is in a rural area, whereas University High School is in a suburban region and Morgantown High School is located in an urban area. The voluntary survey was administered at all three schools during school hours. In all, 2328 surveys were distributed and returned. Of these surveys, however, not all were complete. Students were informed that they did not have to answer any questions they did not wish to. At Clay Battelle, 188 student surveys were at least partially filled, at University High 887 surveys were answered, and at Morgantown High 1257 surveys were answered.

\subsection{Project Schedule}

Due to the inclement weather that comes to West Virginia in the late Fall and Winter, and the limited timeframe for the project, the scheduling of the speed collection and speed trailer installation and removal were critical. To avoid a situation where vehicle speeds were significantly influenced by weather, the speed data collection schedule was accelerated to finish as soon as possible. That being said, data were not collected for the first two weeks of classes at Clay Battelle High School to allow for school travel patterns to settle down and become more routine. Two weeks' of data were collected without any changes to the traffic control or signage, and then the first speed trailer was installed on the westbound approach. Three weeks following that, the eastbound trailer was installed. After five full weeks at the school, the westbound trailer was removed, and speeds continued to be collected for three weeks following its removal. All speed data collection was completed by November 15, 2015: avoiding most if not all of the snowy and icy season. A table detailing the aforementioned schedule can be found below in Table 3-1. 


\begin{tabular}{|l|l|}
\hline \multicolumn{2}{|l|}{ Project Schedule } \\
\hline First day of classes & August $19^{\text {th }}, 2015$ \\
\hline Traffic Tube Installation & September $7^{\text {th }}, 2015$ \\
\hline Data Collection & September $8^{\text {th }}, 2015$ through November $15^{\text {th }}, 2015$ \\
\hline Westbound Trailer Installation & September $20^{\text {th }}, 2015$ \\
\hline Eastbound Trailer Installation & October $6^{\text {th }}, 2015$ \\
\hline Westbound Trailer Removal & October $25^{\text {th }}, 2015$ \\
\hline Student Surveys Administered & December $1^{\text {st }}, 2016$ through December $10^{\text {th }}, 2016$ \\
\hline
\end{tabular}

The data was largely collected without incident, however a few things should be considered. Blacksville, WV experienced rain exceeding 0.1 inches on twelve of the days on which speed data was collected. This threshold is generally a point of daily rainfall at which water begins to accumulate on roads, so it was chosen as the minimum amount of rain considered significant (Rain Measurement, 2013). The speeds on rainy days are compared to those on which there was little or no rainfall in section 4.1. Finally, one of the tubes was cut on Tuesday, October $27^{\text {th }}$. With one tube cut, no speed data could be collected. The tube was replaced by Sunday, November $1^{\text {st }}$, however, and data collection continued. It is believed that the tube was cut as a consequence of the addition of gravel to the school parking lot near the tubes around that time. Unfortunately, these days are missing, but the recorded data is still robust enough to ascertain useful information. Two of those days not recorded because of the cut tube, October $27^{\text {th }}$ and $28^{\text {th }}$, were also recorded as rainy days, leaving ten days of recorded speed data with significant rain. 


\section{Results}

The speed results were divided into categories based on the condition under which speeds were being recorded. First, data was filtered to consider only hours under which the school zone speed limit was in effect. Data was collected continuously 24 hours per day, 7 days per week, but the times of concern are only when children are present at the school, and one hour before and after they are dismissed. Data was then separated by approach direction. Eastbound speeds were considered separately from westbound speeds. Then, data was divided by traffic control condition: pre-existing traffic control, westbound trailer only, both trailers, and eastbound trailer only. The eastbound trailer was not considered at any point for the westbound approach, as it was not easily visible from that approach at the point that the speeds were collected. Each category was then further broken down into dry and rainy days. The data were then fit to distributions and analyzed.

\subsection{Speed Study Analysis}

\section{Rainy Days}

Comparing rainy days to clear days for each condition and conducting t-tests to determine the statistical significance of any differences in speeds, the following table was produced (Table 4-1). "WB" indicates the westbound approach and "EB" indicates the eastbound approach. The difference is calculated as the average speed under dry weather conditions minus the average speed under rainy weather conditions for each studied traffic control condition. 


\begin{tabular}{|c|c|c|c|c|c|c|}
\hline \multicolumn{7}{|c|}{ Rain vs. Dry Average Speeds (Avg.Dry - Avg.Rain) } \\
\hline Condition & $\begin{array}{c}\text { Difference } \\
\text { (mph) }\end{array}$ & t-stat & $\begin{array}{c}\text { Degrees of } \\
\text { Freedom }\end{array}$ & $\begin{array}{c}\text { p-value } \\
\text { 95\% Significance }\end{array}$ & \\
\hline WB-pre & 0.58 & 3.858 & 4264.992 & 0.000058 & Yes & Clear>Rain \\
\hline WB-with & -0.37 & 3.896 & 12338.135 & 0.000049 & Yes & Rain>Clear \\
\hline WB-post & 0.57 & 4.067 & 5477.079 & 0.000024 & Yes & Clear>Rain \\
\hline EB-pre & 0.39 & 3.172 & 4632.387 & 0.0008 & Yes & Clear>Rain \\
\hline EB-w/WB & 0.01 & 0.135 & 10352.71 & 0.4462 & No & Clear=Rain \\
\hline EB-both & -0.40 & 3.249 & 3702.437 & 0.0006 & Yes & Rain>Clear \\
\hline EB-only & 0.82 & 7.701 & 6289.718 & 0.0000 & Yes & Clear>Rain \\
\hline
\end{tabular}

Table 4-1: Rain vs. Dry Comparison Table

Despite fairly small average speed differences between rainy and clear conditions, the average speeds were significantly different for every condition excluding the eastbound speeds with only the westbound-facing trailer. This is likely a function of the large sample size and small variances observed for each condition. While the researcher would expect for average speeds to be lower in the presence of rain, for two conditions the opposite was true. For the EBboth and WB-with conditions, the average speeds with rain were actually slightly higher than the speeds without rain. This is unexpected, and may reflect a level of comfort afforded to drivers in the presence of the speed trailers. The rainy days were removed from further analysis as their presence could disrupt the results for tests of other conditions.

\section{Distribution Fits}

With the extensive speed data available, vehicle speeds for each traffic control condition could be fit to a distribution and analyzed probabilistically. The recorded speeds for each condition were separated and checked for distribution fits using the 'distrfitplus' package in R. First, speeds were plotted in empirical density plots and cumulative distribution functions, as in Figure 4-1 below, to determine shapes of the distribution. As all plots were similarly shaped, it was determined that normal and log-normal distributions would both be potentially strong fits. 
Speeds for each traffic control condition were then fit to a normal and lognormal distribution using the software package and the fitted distributions were plotted against the histogram of the data and cumulative density functions, with Q-Q and P-P plots to compare the fits as in Figure 4-2. Goodness of fit statistics and criteria were produced for each condition, and are presented below in Table 4-2 through Table 4-8. For all conditions, with the exception of the westbound approach speeds with the westbound trailer installed (Figure 4-11, Figure 4-12, Table 4-7), the normal distribution fit was slightly stronger than the lognormal distribution fit. For these cases, all goodness-of-fit statistics and criteria were lower for normal than lognormal. Despite the opposite being true for the aforementioned condition, the goodness-of-fit is still acceptably strong. For the sake of consistency, the normal distribution fits were used for further analysis of all conditions of the speed data. 
Empirical density

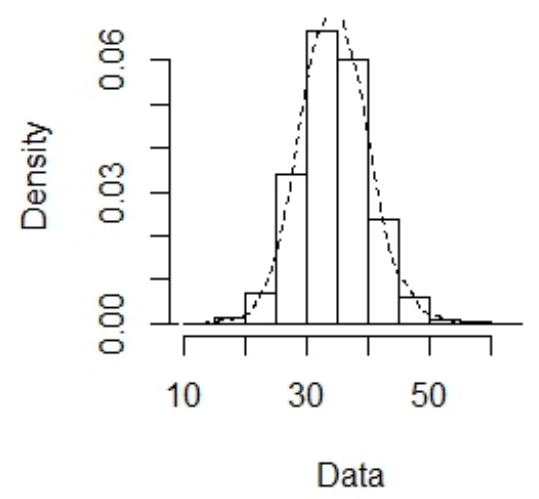

Cumulative distribution

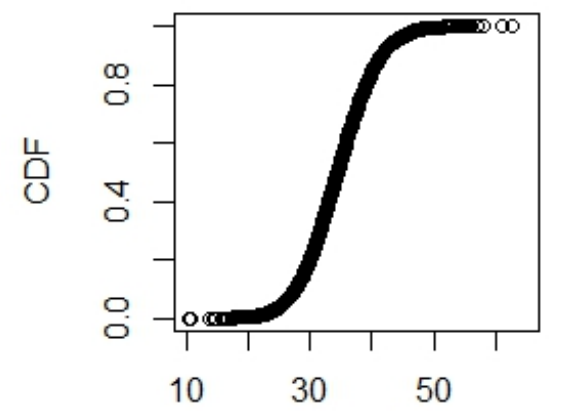

Data

Figure 4-1: Eastbound speeds before trailers empirical density plot and cumulative distribution function
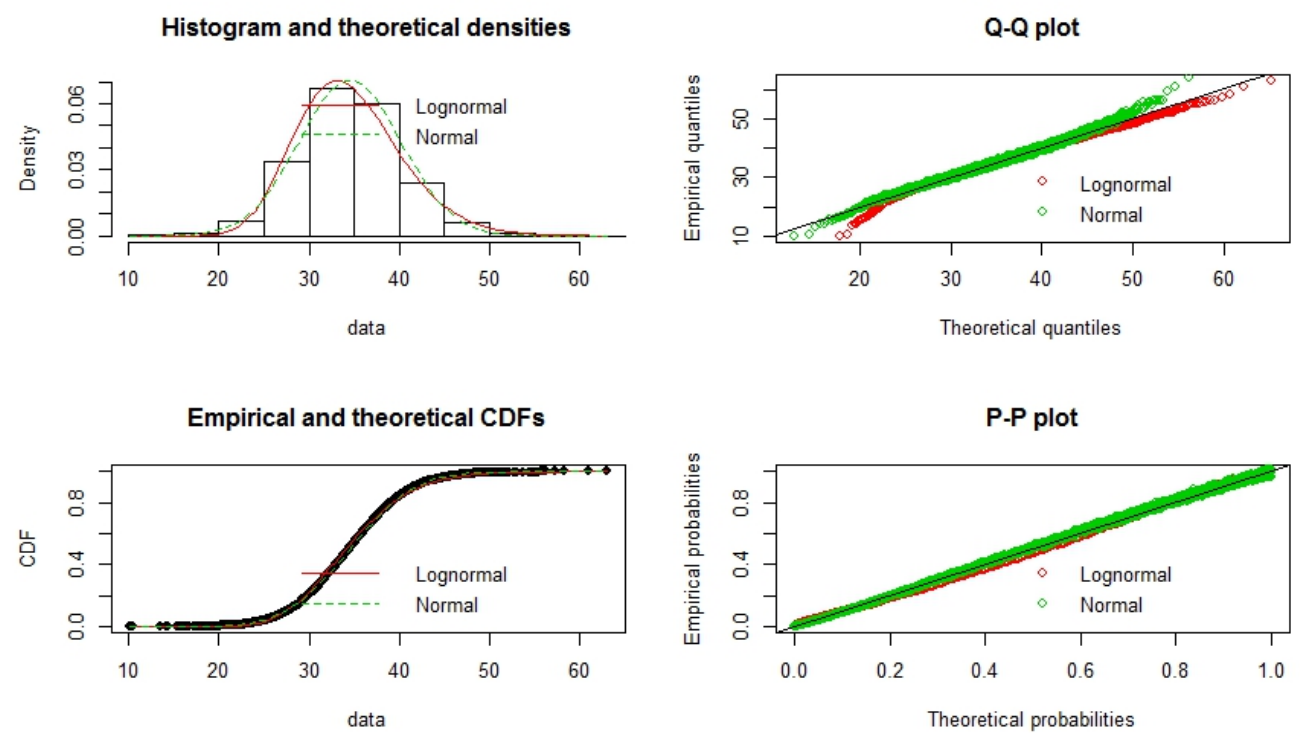

Figure 4-2: Eastbound speeds before trailers normal and lognormal distribution fit comparison

Eastbound- Pre

\begin{tabular}{|l|r|r|}
\hline Goodness-of-fit Statistics & \multicolumn{1}{|c|}{ Log-normal } & Normal \\
\hline Kolmogorov-Smirnov statistic & 0.03154975 & 0.01707226 \\
\hline Cramer-von Mises statistic & 2.67727816 & 0.5131032 \\
\hline Anderson-Darling statistic & 17.00184848 & 3.83875767 \\
\hline Goodness-of-fit Criteria & Log-normal & Normal \\
\hline Aikake's Information Criterion & 51981.85 & 51704.44 \\
\hline Bayesian Information Criterion & 51995.87 & 51718.47 \\
\hline
\end{tabular}

Table 4-2: Eastbound pre-speed trailer speed distribution fit statistics and criteria 

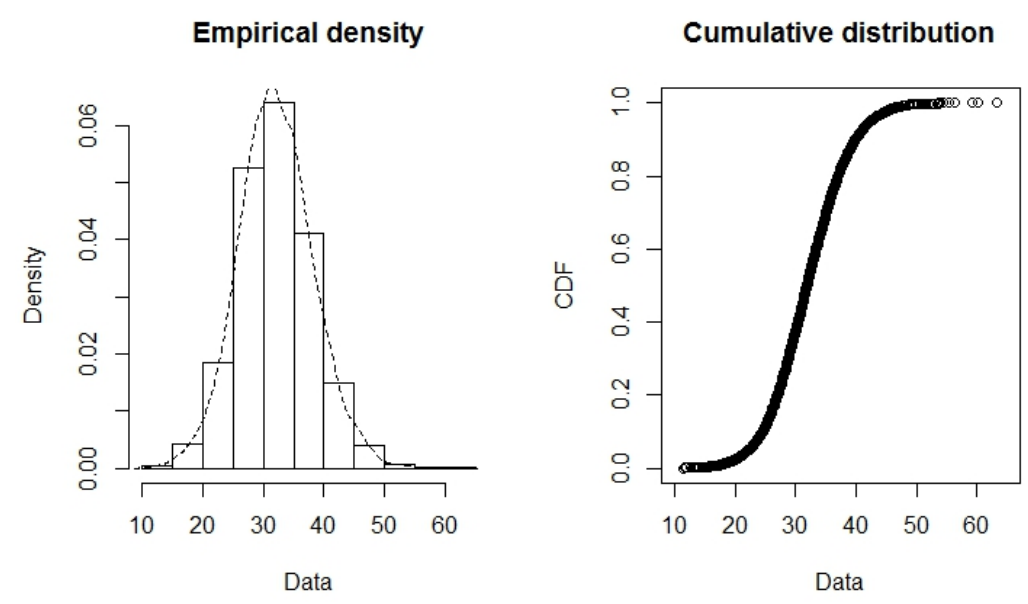

Figure 4-3: Eastbound speeds with westbound trailer empirical density plot and cumulative distribution function
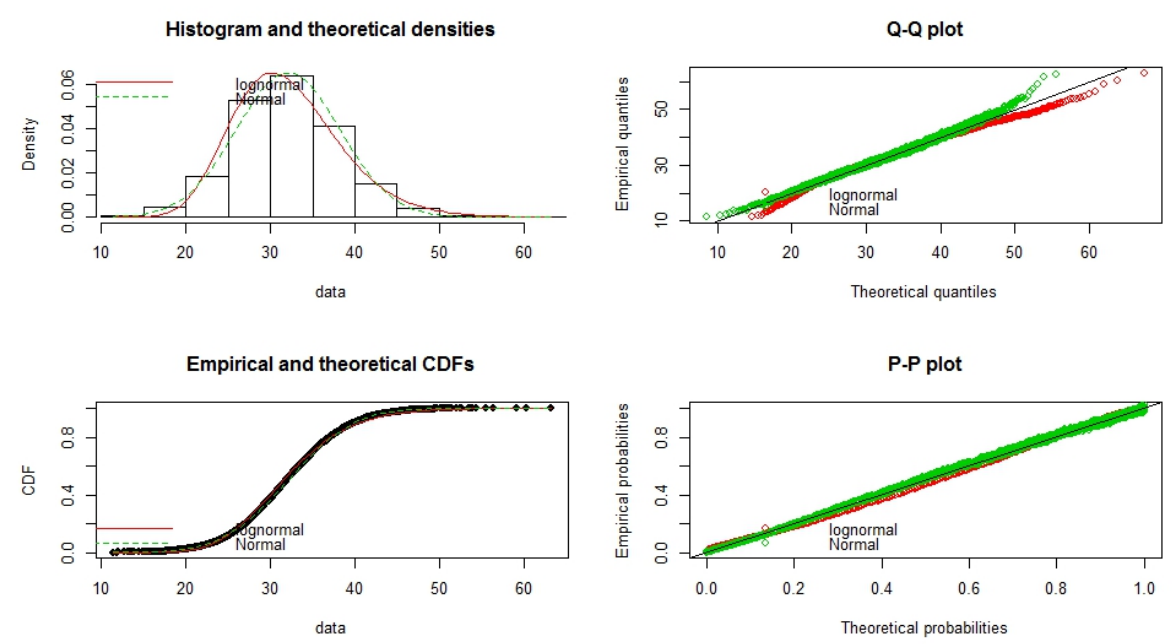

Figure 4-4: Eastbound speeds with westbound trailer normal and lognormal distribution fit plots

\section{Eastbound- with WB}

\begin{tabular}{|l|c|l|}
\hline Goodness-of-fit Statistics & Log-normal & Normal \\
\hline Kolmogorov-Smirnov statistic & 0.03747848 & 0.01772086 \\
\hline Cramer-von Mises statistic & 3.12158631 & 0.57811462 \\
\hline Anderson-Darling statistic & 20.69653239 & 3.55086279 \\
\hline Goodness-of-fit Criteria & Log-normal & Normal \\
\hline Aikake's Information Criterion & 50690.85 & 50394.24 \\
\hline Bayesian Information Criterion & 50704.77 & 50408.17 \\
\hline
\end{tabular}

Table 4-3: Eastbound with westbound trailer speed distribution fit statistics and criteria 

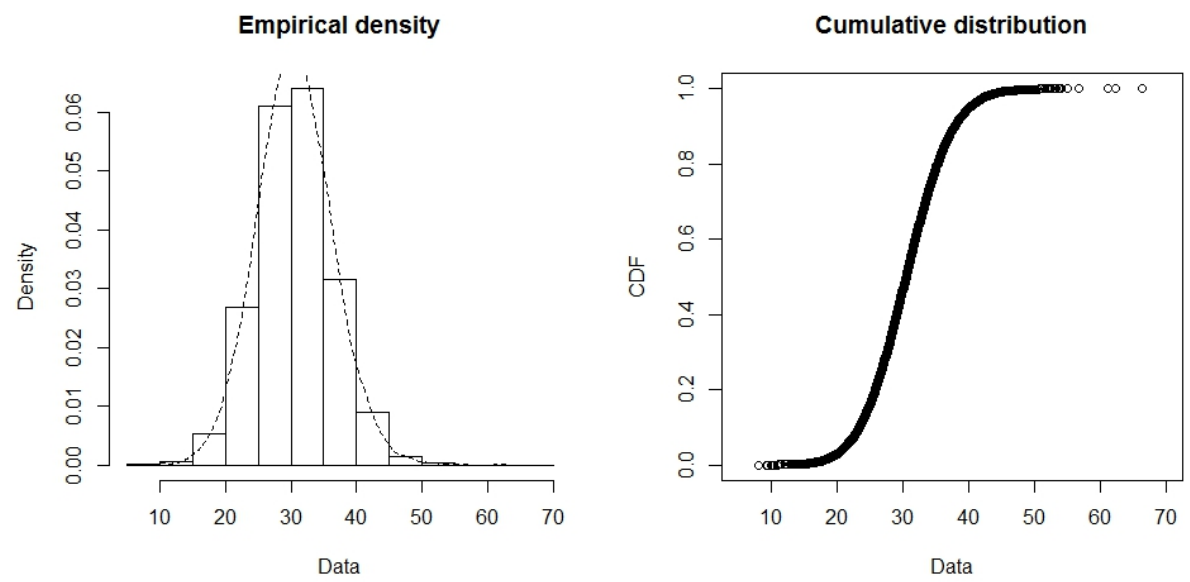

Figure 4-5: Eastbound speeds with both trailers empirical density plot and cumulative distribution function
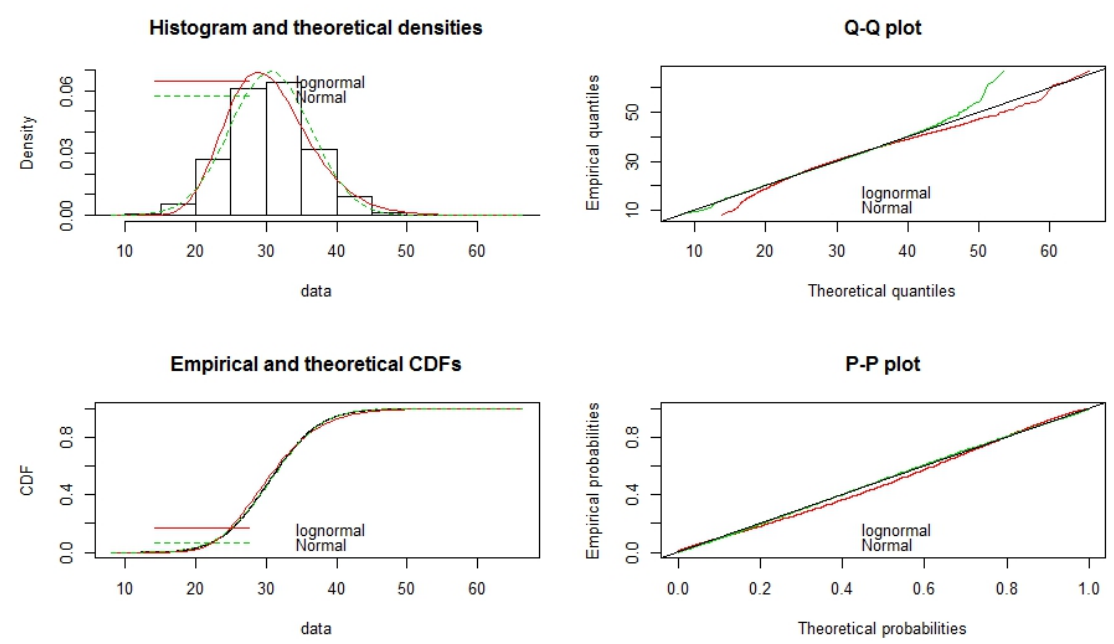

Figure 4-6: Eastbound speeds with both trailers normal and lognormal distribution fit plots

\section{Eastbound- with both}

\begin{tabular}{|l|c|c|}
\hline Goodness-of-fit Statistics & \multicolumn{1}{|c|}{ Log-normal } & Normal \\
\hline Kolmogorov-Smirnov statistic & 0.04038018 & 0.01427374 \\
\hline Cramer-von Mises statistic & 6.88167986 & 0.61178553 \\
\hline Anderson-Darling statistic & 42.72168194 & 3.90858637 \\
\hline Goodness-of-fit Criteria & Log-normal & Normal \\
\hline Aikake's Information Criterion & 92393.78 & 91786.2 \\
\hline Bayesian Information Criterion & 92408.94 & 91801.36 \\
\hline
\end{tabular}

Table 4-4: Eastbound with both trailers speed distribution fit statistics and criteria 

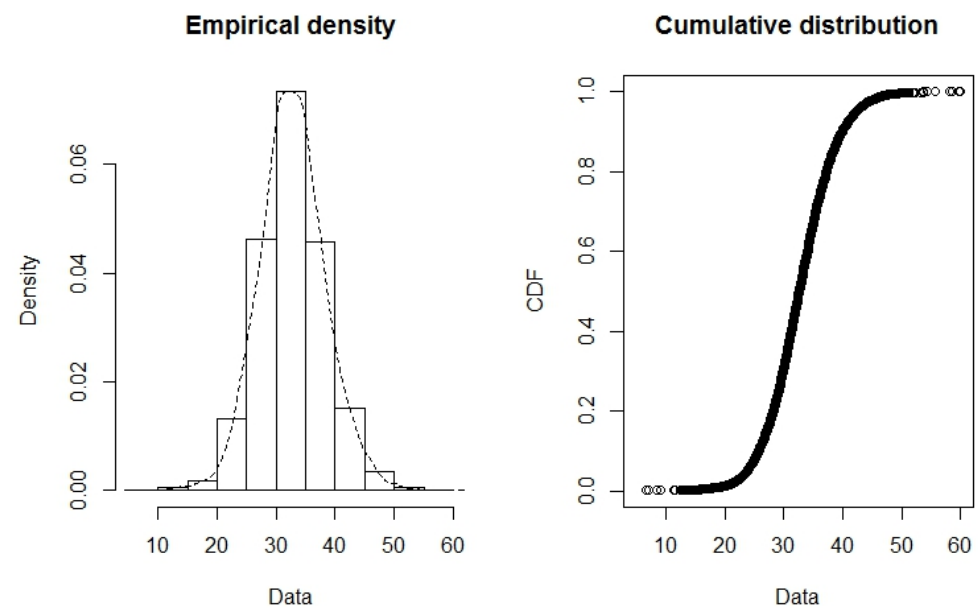

Figure 4-7: Eastbound speeds with eastbound trailer empirical density plot and cumulative distribution function
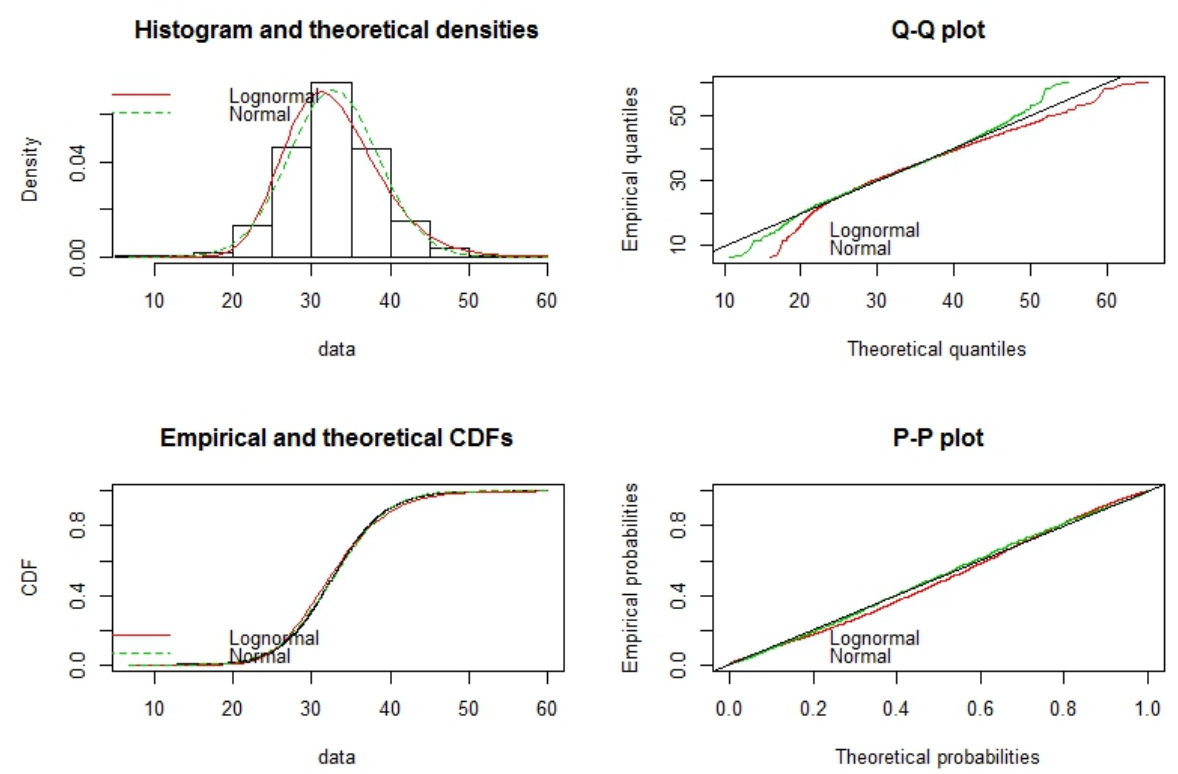

Figure 4-8: Eastbound speeds with eastbound trailer normal and lognormal distribution fit plots

\section{Eastbound- with EB}

\begin{tabular}{|l|c|l|}
\hline Goodness-of-fit Statistics & Log-normal & Normal \\
\hline Kolmogorov-Smirnov statistic & 0.04351993 & 0.02315413 \\
\hline Cramer-von Mises statistic & 5.46067393 & 1.14819915 \\
\hline Anderson-Darling statistic & 33.53005868 & 7.34821439 \\
\hline Goodness-of-fit Criteria & Log-normal & Normal \\
\hline Aikake's Information Criterion & 66589.01 & 65955 \\
\hline Bayesian Information Criterion & 66603.52 & 65969.51 \\
\hline
\end{tabular}

Table 4-5: Eastbound with eastbound trailer only speed distribution fit statistics and criteria 

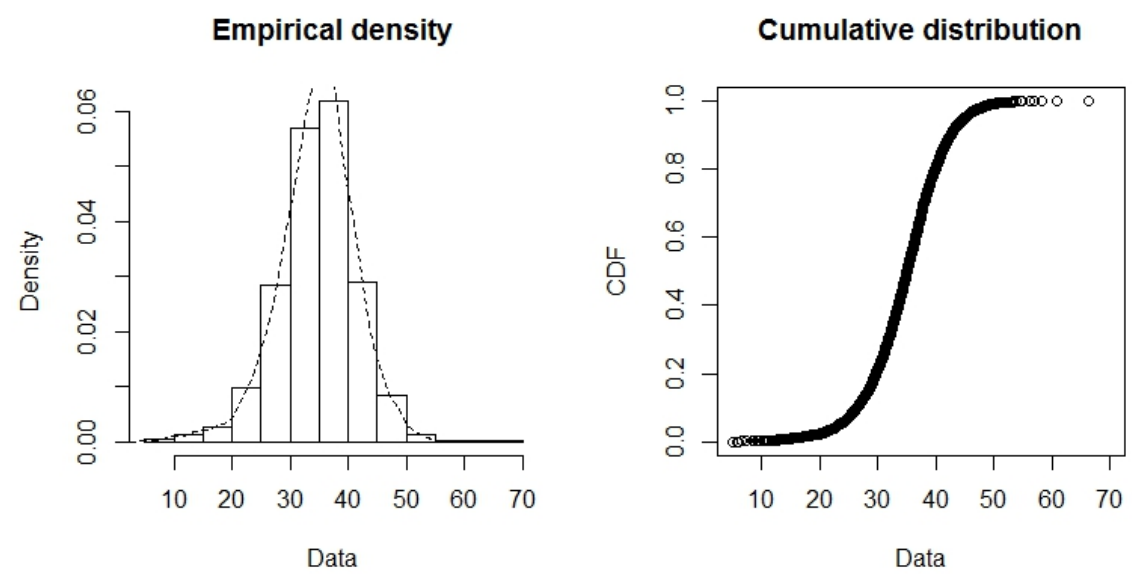

Figure 4-9: Westbound speeds before speed trailers empirical density and cumulative distribution plots
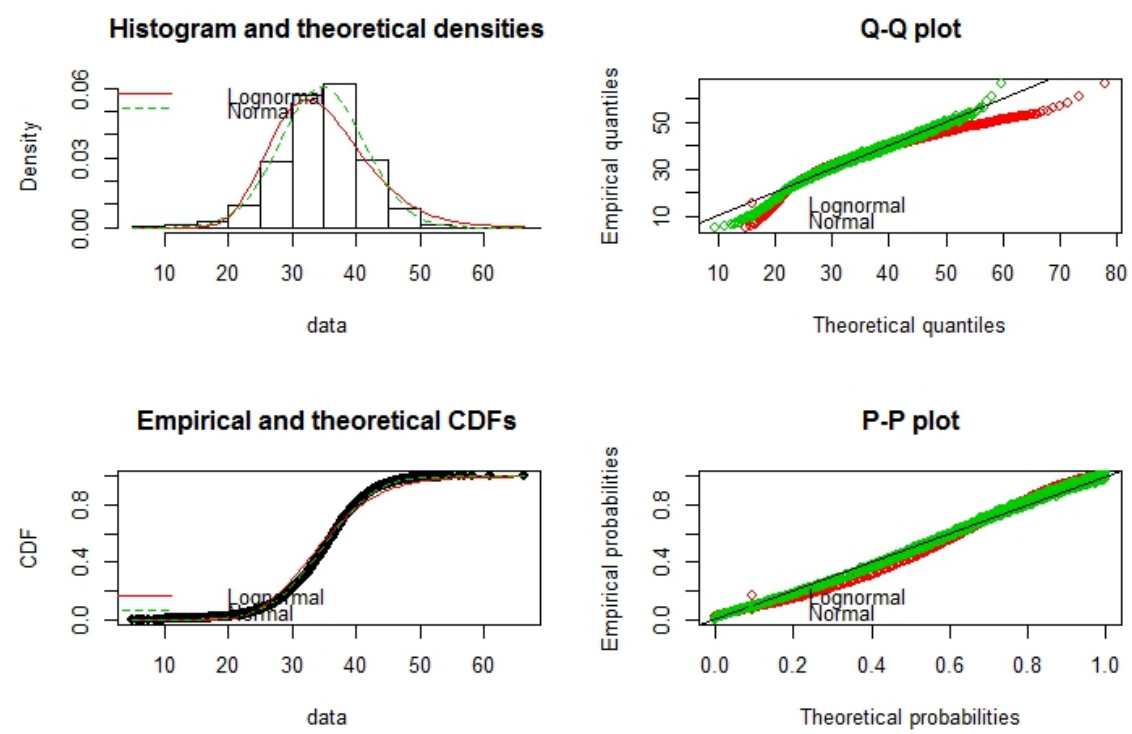

Figure 4-10: Westbound speeds before speed trailers normal and lognormal distribution fit plots

\section{Westbound- pre}

\begin{tabular}{|l|r|c|}
\hline Goodness-of-fit Statistics & Log-normal & Normal \\
\hline Kolmogorov-Smirnov statistic & 0.09016644 & 0.03964275 \\
\hline Cramer-von Mises statistic & 21.34581932 & 3.24713341 \\
\hline Anderson-Darling statistic & 128.7183336 & 19.95729612 \\
\hline Goodness-of-fit Criteria & Log-normal & Normal \\
\hline Aikake's Information Criterion & 52413.71 & 50657.65 \\
\hline Bayesian Information Criterion & 52427.6 & 50671.54 \\
\hline
\end{tabular}

Table 4-6: Westbound pre-speed trailer speed distribution fit statistics and criteria 

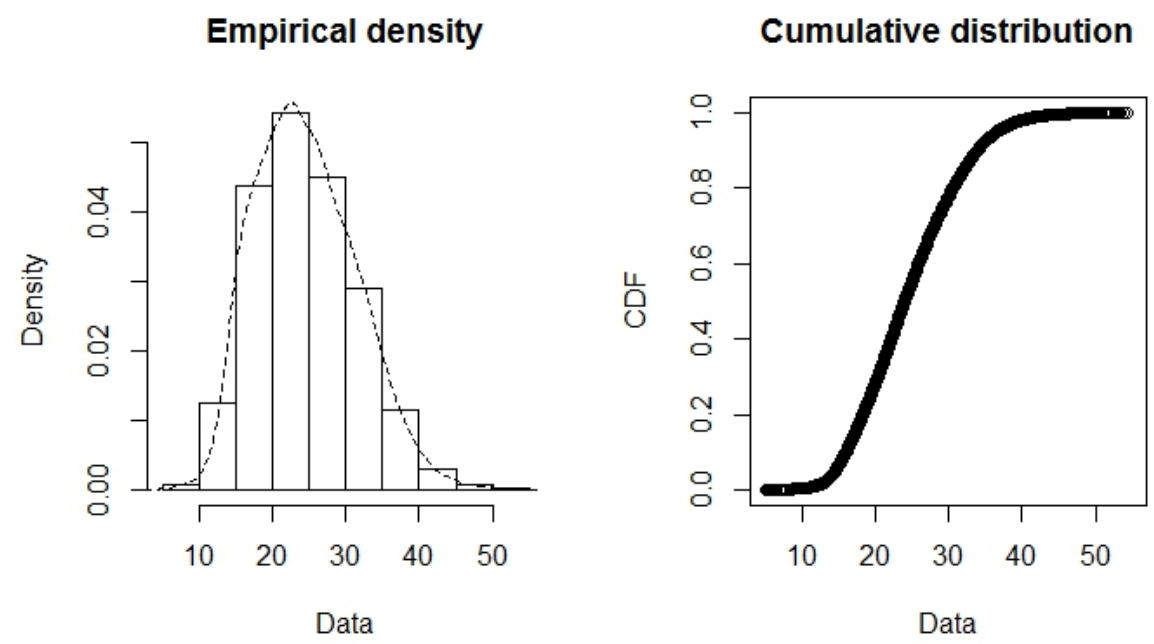

Figure 4-11: Westbound speeds with westbound speed trailer empirical density and cumulative distribution plots
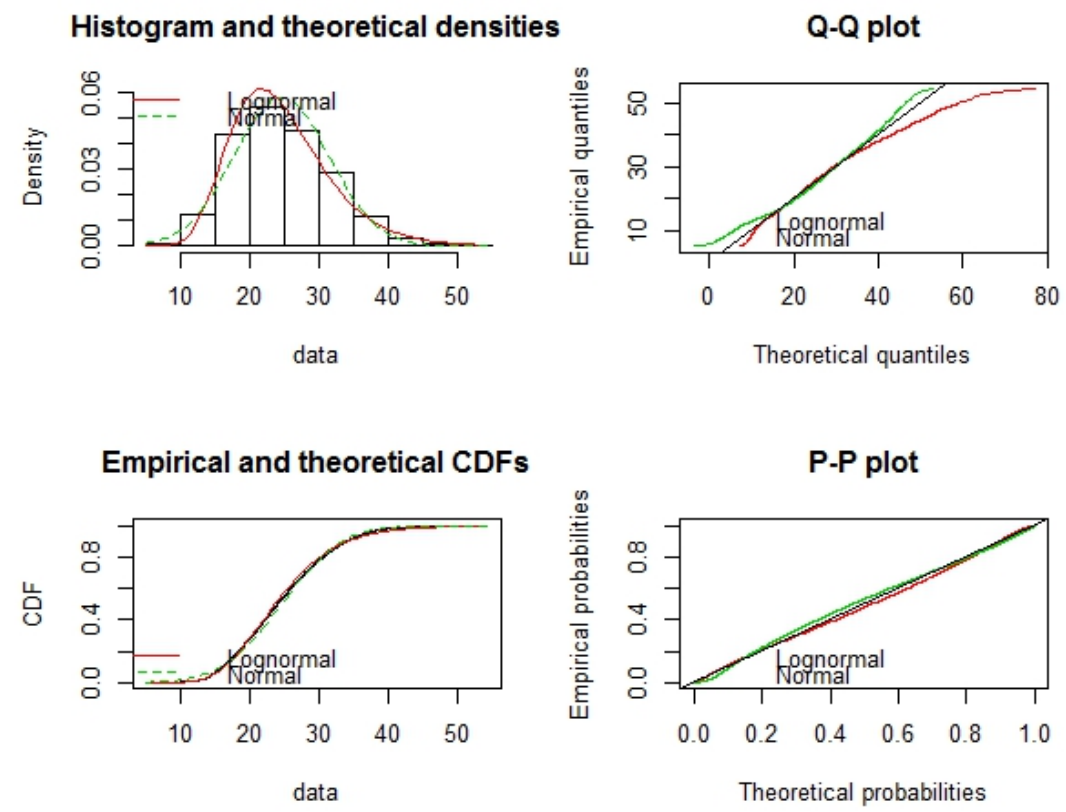

Figure 4-12: Westbound speeds with westbound trailer normal and lognormal distribution fit plots

Westbound- with

\begin{tabular}{|l|c|c|}
\hline Goodness-of-fit Statistics & Log-normal & \multicolumn{1}{|c|}{ Normal } \\
\hline Kolmogorov-Smirnov statistic & 0.02909094 & 0.04028681 \\
\hline Cramer-von Mises statistic & 5.64442352 & 11.14213225 \\
\hline Anderson-Darling statistic & 36.08853782 & 73.30065883 \\
\hline Goodness-of-fit Criteria & Log-normal & Normal \\
\hline Aikake's Information Criterion & 147719.7 & 148222.9 \\
\hline Bayesian Information Criterion & 147735.7 & 148238.9 \\
\hline
\end{tabular}


Table 4-7: Westbound with speed trailer speed distribution fit statistics and criteria
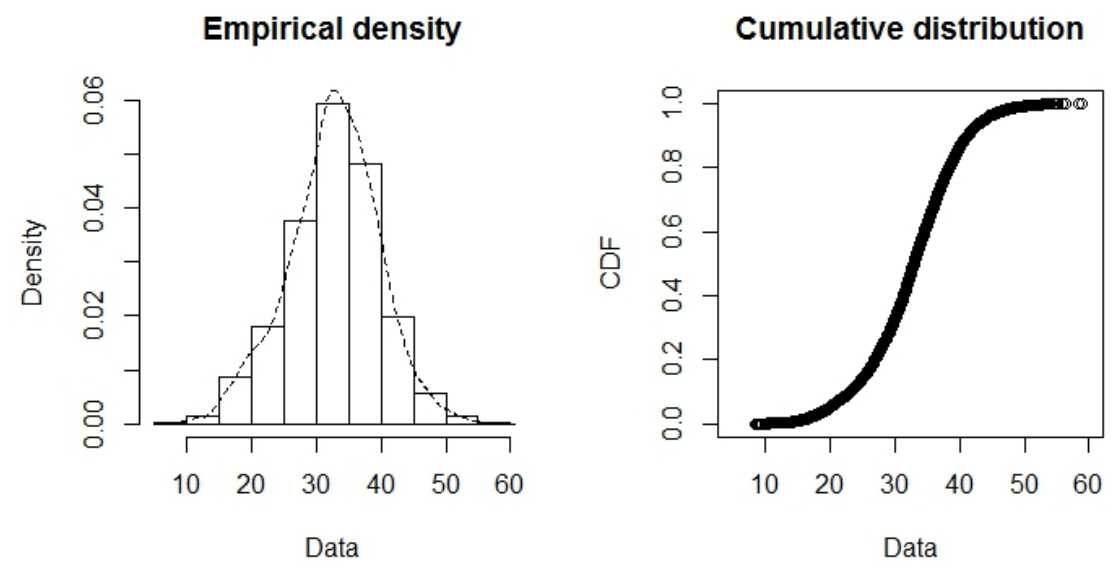

Figure 4-13: Westbound speeds after trailer removal empirical density and cumulative density plots
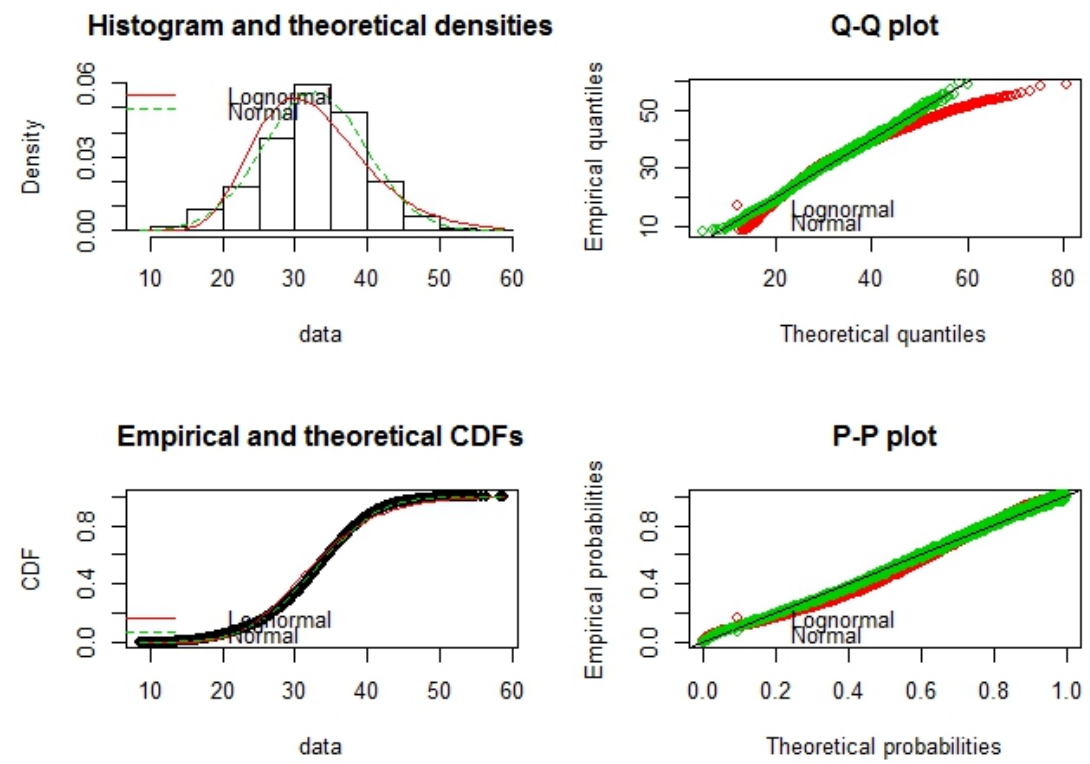

Figure 4-14: Westbound speeds after trailer removal normal and lognormal distribution fit plots

Westbound-Post

\begin{tabular}{|l|c|c|}
\hline Goodness-of-fit Statistics & \multicolumn{1}{|c|}{ Log-normal } & Normal \\
\hline Kolmogorov-Smirnov statistic & 0.08512531 & 0.03510189 \\
\hline Cramer-von Mises statistic & 20.61318741 & 2.33327122 \\
\hline Anderson-Darling statistic & 122.132524 & 14.03322238 \\
\hline Goodness-of-fit Criteria & Log-normal & Normal \\
\hline Aikake's Information Criterion & 65690.09 & 64347.67 \\
\hline Bayesian Information Criterion & 65704.42 & 64361.99 \\
\hline
\end{tabular}

Table 4-8: Westbound post-speed trailer speed distribution fit statistics and criteria 
Using the fitted normal distributions, the probability that speeds were within $5 \mathrm{mph}$ of the 15 mph school zone speed limit were computed and are shown below in Table 4-9. The computed probabilities are below $4 \%$ for all conditions excluding the westbound speeds in the presence of the westbound-facing speed trailer. In this condition, the fitted distribution predicts that $25.36 \%$ of vehicles traveled at $20 \mathrm{mph}$ or slower when entering the school zone. This still reflects a considerably lower than expected compliance with school zone speed limits, but demonstrates that speed trailers show promise for improving drivers' awareness of and compliance with posted school zone speed limits. The eastbound speeds, measured as vehicles leave the school zone, were influenced by the presence of the westbound trailer alone, as $0.52 \%$ of vehicles were expected to meet the compliance criteria before the trailer was installed while $2.45 \%$ of vehicles are expected to meet the criteria after its installation.

Normal Distribution Fits

\begin{tabular}{|l|r|r|r|}
\hline Condition & \multicolumn{1}{|l|}{ Mean } & Std Dev & P(<20mph) \\
\hline EB-pre & 34.5233 & 5.66276 & $0.52 \%$ \\
\hline EB-with WB & 32.0861 & 6.13814 & $2.45 \%$ \\
\hline EB-with both & 30.5794 & 5.76537 & $3.33 \%$ \\
\hline EB-with EB & 32.7580 & 5.66097 & $1.21 \%$ \\
\hline WB-pre & 34.7080 & 6.58819 & $1.28 \%$ \\
\hline WB-with & 24.5817 & 6.90857 & $25.36 \%$ \\
\hline WB-post & 32.6437 & 7.09249 & $3.73 \%$ \\
\hline
\end{tabular}

Table 4-9: Normal distribution fits and probability of speeds being less than $20 \mathrm{mph}$

\section{Compliance}

As reflected by the distribution fits above, compliance with the school zone speed limit is extremely low at Clay Battelle High School. This is likely because the school zone is along a highway with high speeds. A relatively abrupt, time sensitive drop in speed limit is inconvenient and difficult to accomplish. Because actual compliance rates with the $15 \mathrm{mph}$ school zone speed limit were so low, compliance rates were considered as vehicles within $5 \mathrm{mph}$ of the posted 
school speed limit (vehicles travelling $20 \mathrm{mph}$ or less) using the recorded speed data. Still, no more than $29 \%$ of vehicles traveled $20 \mathrm{mph}$ or slower for any of the conditions examined.

\begin{tabular}{|l|r|r|r|}
\hline West Bound & \multicolumn{1}{|l|}{ Pre } & \multicolumn{1}{l|}{ With } & \multicolumn{1}{l|}{ Post } \\
\hline Avg. & 34.71 & 24.58 & 32.64 \\
\hline Std Dev. & 6.59 & 6.90 & 7.09 \\
\hline Count & 7665 & 21801 & 9524 \\
\hline$\%$ within $5 \mathrm{mph}$ & $2.22 \%$ & $28.89 \%$ & $5.20 \%$ \\
\hline
\end{tabular}

Table 4-10: Westbound Average Speed, Standard Deviation and Percent Compliance

\begin{tabular}{|l|r|r|r|r|}
\hline East Bound & Pre & With-WB & With-Both & With-EB \\
\hline Avg. & 34.52 & 32.09 & 30.58 & 32.76 \\
\hline Std Dev. & 5.66 & 6.14 & 5.77 & 5.66 \\
\hline Count & 8199 & 7792 & 14473 & 10460 \\
\hline$\%$ within $5 \mathrm{mph}$ & $0.54 \%$ & $0.77 \%$ & $3.30 \%$ & $1.22 \%$ \\
\hline
\end{tabular}

Table 4-11: Eastbound Average Speed, Standard Deviation and Percent Compliance

Compliance rates for the westbound approach were uniformly higher, which suggests that those entering into the school zone were more likely to comply with the speed limit than drivers exiting the school zone. This may reflect a pattern of drivers slowing for the speed trailers and speed limit signs when entering the school zone, and accelerating while leaving the school zone. This could also be a function of the geometry and speed limits of the different approaches.

\section{Mornings and Afternoons}

Traffic in and around schools is often very different when comparing morning drop-off times and afternoon pick-up times. The morning hours are more likely to coincide with morning rush-hour traffic, especially along a highway, which may be used for non-school related travel to and from work. In West Virginia and other northern regions, visibility may also be more of a concern in the mornings, as the sun may not rise fully until school has already started. For these reason, speeds were separated into two-hour blocks each day for each condition: 6:30 AM to 8:30 AM and 1:30 PM to 3:30 PM. With school at Clay Battelle starting at 7:30 AM and ending 
at 3:30 PM, these categories were created to capture the morning drop-off and afternoon pick-up traffic through the school zone.

For the t-tests below, the null hypothesis is that the speeds are the same for the morning and afternoon while the alternate hypothesis is that the afternoon speeds are greater than the morning speeds.

\begin{tabular}{|l|r|r|r|r|l|l|}
\hline \multicolumn{7}{|c|}{ Morning vs. Afternoon Average Speeds (Avg.Morning-Avg.Afternoon) } \\
\hline Test & Difference & \multicolumn{1}{|c|}{ T-stat } & \multicolumn{1}{|l|}{ DoF } & \multicolumn{1}{l|}{ p-value } & 95\% Significance & Conclusion \\
\hline WB-pre & 0.05 & 0.228 & 4351.746 & 0.409732 & No & Morn.=Afternoon \\
\hline WB-with & -0.41 & 3.417 & 13167.917 & 0.000318 & Yes & Afternoon>Morn. \\
\hline WB-post & -2.67 & 13.896 & 5304.511 & 0.000000 & Yes & Afternoon>Morn. \\
\hline EB-pre & -0.37 & 2.008 & 3858.649 & 0.0224 & Yes & Afternoon>Morn. \\
\hline EB- & & & & & & \\
w/WB & 0.19 & 0.949 & 3785.487 & 0.1712 & No & Morn.=Afternoon \\
\hline EB-both & -0.47 & 3.282 & 7022.465 & 0.0005 & Yes & Afternoon $>$ Morn. \\
\hline EB-only & -0.56 & 4.397 & 5017.632 & 0.0000 & Yes & Afternoon $>$ Morn. \\
\hline
\end{tabular}

Table 4-12: Morning vs. Afternoon T-Tests

For all but two of the conditions, afternoon speeds were measured to be significantly faster than morning speeds. The differences in average speeds were less than $0.6 \mathrm{mph}$ for all conditions excluding the westbound approach after the removal of the westbound-facing speed trailer. Most of these differences are slight, near $0.5 \mathrm{mph}$ or less. The average morning to afternoon speed difference was largest for the westbound approach after the removal of the speed trailer.

\section{Before and After}

Beyond all of the above considerations, the aim of the speed study is to determine the effectiveness of speed monitoring displays and similar traffic control devices in improving school zone speed limit compliance. By analyzing each traffic control condition as compared with the speeds observed before any speed trailers were installed, the following hypothesis tests 
were performed (Table 4-13). The null hypothesis for these tests is that there is no change in average speeds in the post-speed trailer conditions as compared to the pre-speed trailer condition. The alternate hypothesis is that the average pre-trailer speeds are higher than the average posttrailer speeds for each traffic control condition respectively. The last hypothesis test considers the eastbound approach and whether average speeds with the westbound facing trailer present were slower than the average speeds with it removed. For this test, the null hypothesis is that the average eastbound speed is unchanged with or without the westbound trailer, and the alternate hypothesis is that average eastbound speeds are higher without the westbound trailer.

\begin{tabular}{|l|r|r|r|r|l|l|}
\hline \multicolumn{7}{|c|}{ Before/After Average Speeds (Avg. Before-Avg.After) } \\
\hline Test & Difference & T-stat & \multicolumn{1}{|l|}{ DoF } & p-value & $\begin{array}{l}\text { 95\% } \\
\text { Significance }\end{array}$ & Conclusion \\
\hline WB-with & 10.13 & 114.304 & 13984.7 & 0.000 & Yes & Pre>With \\
\hline WB-post & 2.06 & 19.731 & 16838.7 & 0.000 & Yes & Pre> Post \\
\hline EB-w/ WB & 2.44 & 26.059 & 15718.5 & 0.000 & Yes & Pre>WB only \\
\hline EB-both & 3.94 & 50.054 & 17277.6 & 0.000 & Yes & $\begin{array}{l}\text { Pre }>\text { With } \\
\text { Both }\end{array}$ \\
\hline EB-EB only & 1.77 & 21.137 & 17604.7 & 0.000 & Yes & Pre>EB only \\
\hline $\begin{array}{l}\text { EB-only/EB- } \\
\text { both }\end{array}$ & 2.18 & 29.755 & 22769.7 & 0.000 & Yes & EB Only>Both \\
\hline
\end{tabular}

Table 4-13: Before and after speed trailer hypothesis tests of speed reduction

For these tests, every single condition (including the condition after the removal of the westbound trailer) shows a significant reduction in speeds with the presence of speed trailers. Even the eastbound approach speeds were slowed significantly by the addition of the westboundfacing speed trailer. Also, the eastbound speeds exiting the school zone were significantly lower with both eastbound facing and westbound facing trailers installed and compared to speeds with only the eastbound trailer. Similar tests were conducted to see if the differences observed were significant at $2 \mathrm{mph}, 5 \mathrm{mph}, 9 \mathrm{mph}$ and $10 \mathrm{mph}$ thresholds. These tests are shown in Table 4-14, Table 4-15, Table 4-16, and Table 4-17 respectively. 


\begin{tabular}{|l|r|r|r|r|l|l|}
\hline \multicolumn{7}{|c|}{ Before/After Average Speeds (Avg. Before-Avg.After $>2 \mathrm{mph}$ ) } \\
\hline Test & Difference & \multicolumn{1}{|c|}{ T-stat } & \multicolumn{1}{c|}{ DoF } & p-value & $\begin{array}{l}\mathbf{9 5 \%} \\
\text { Significance }\end{array}$ & \\
\hline WB-with & 10.13 & 91.727 & 13984.7 & 0.000 & Yes & Pre - 2>With \\
\hline WB-post & 2.06 & 0.615 & 16838.7 & 0.269 & No & Pre - 2<Post \\
\hline EB-w/ WB & 2.44 & 4.675 & 15718.5 & 0.000 & Yes & Pre - 2>WB only \\
\hline EB-both & 3.94 & 24.671 & 17277.6 & 0.000 & Yes & Pre - 2>With Both \\
\hline EB-EB only & 1.77 & -2.810 & 17604.7 & 0.002 & No & Pre - 2<EB only \\
\hline EB-only/EB-both & 2.18 & 2.439 & 22769.7 & 0.007 & Yes & EB Only - 2>Both \\
\hline
\end{tabular}

Table 4-14: Before and after speed trailer hypothesis test of $2 \mathrm{mph}$ speed reduction

\begin{tabular}{|l|r|l|l|r|l|l|}
\hline \multicolumn{7}{|c|}{ Before/After Average Speeds (Avg. Before-Avg.After $>5 \mathrm{mph}$ ) } \\
\hline Test & Difference & T-stat & \multicolumn{1}{l|}{ DoF } & p-value & $\begin{array}{l}\mathbf{9 5 \%} \\
\text { Significance }\end{array}$ & \\
\hline WB-with & 10.13 & 57.862 & 13984.7 & 0.000 & Yes & Pre $-5>$ With \\
\hline WB-post & 2.06 & -28.060 & 16838.6 & 0.000 & No & Pre $-5<$ Post \\
\hline EB-w/ WB & 2.44 & -27.401 & 15718.5 & 0.000 & No & Pre $-5<$ WB only \\
\hline EB-both & 3.94 & -13.403 & 17277.5 & 0.000 & No & Pre $-5<$ With Both \\
\hline EB-EB only & 1.77 & -38.729 & 17604.6 & 0.000 & No & Pre $-5<$ EB only \\
\hline EB-only/EB-both & 2.18 & -38.535 & 22769.6 & 0.000 & No & EB Only $-5<$ Both \\
\hline
\end{tabular}

Table 4-15: Before and after speed trailer hypothesis tests of $5 \mathrm{mph}$ speed reduction

\begin{tabular}{|l|r|r|l|r|l|l|}
\hline \multicolumn{7}{|c|}{ Before/After Average Speeds (Avg. Before-Avg.After $>9 \mathrm{mph}$ ) } \\
\hline Test & Difference & T-stat & \multicolumn{1}{l|}{ DoF } & p-value & $\begin{array}{l}\mathbf{9 5 \%} \\
\text { Significance }\end{array}$ & \\
\hline WB-with & 10.13 & 12.71 & 13984.7 & 0.000 & Yes & Pre $-5>$ With \\
\hline WB-post & 2.06 & -66.29 & 16838.7 & 0.000 & No & Pre $-5<$ Post \\
\hline EB-w/ WB & 2.44 & -70.17 & 15718.5 & 0.000 & No & Pre $-5<$ WB only \\
\hline EB-both & 3.94 & -64.17 & 17277.6 & 0.000 & No & Pre - 5<With Both \\
\hline EB-EB only & 1.77 & -86.62 & 17604.7 & 0.000 & No & Pre $-5<$ EB only \\
\hline EB-only/EB-both & 2.18 & -93.17 & 22769.7 & 0.000 & No & EB Only -5<Both \\
\hline
\end{tabular}

Table 4-16: Before and after speed trailer hypothesis tests of $9 \mathrm{mph}$ speed reduction

\begin{tabular}{|l|r|r|r|r|l|l|}
\hline \multicolumn{7}{|c|}{ Before/After Average Speeds (Avg. Before-Avg.After $>10 \mathrm{mph}$ ) } \\
\hline & Difference & T-stat & \multicolumn{1}{|c|}{ DoF } & p-value & $\begin{array}{l}\mathbf{9 5 \%} \\
\text { Significance }\end{array}$ & \\
\hline WB-with & 10.13 & 1.42 & 13984.7 & 0.078 & No & Pre $-10>$ With \\
\hline WB-post & 2.06 & -75.85 & 16838.7 & 0.000 & No & Pre $-10<$ Post \\
\hline EB-w/ WB & 2.44 & -80.86 & 15718.5 & 0.000 & No & Pre $-10<$ WB only \\
\hline EB-both & 3.94 & -76.86 & 17277.6 & 0.000 & No & Pre $-10<$ With Both \\
\hline EB-EB only & 1.77 & -98.60 & 17604.7 & 0.000 & No & Pre $-10<$ EB only \\
\hline EB-only/EB-both & 2.18 & -106.82 & 22769.7 & 0.000 & No & EB Only-10<Both \\
\hline
\end{tabular}

Table 4-17: Before and after speed trailer hypothesis test of $10 \mathrm{mph}$ speed reduction 
For the $2 \mathrm{mph}$ difference threshold, significant differences were observed in three conditions: the eastbound approach when only the westbound trailer was installed, the eastbound approach with both trailers, and the westbound approach with the trailer. For the $5 \mathrm{mph}$ and 9 mph difference thresholds, only the westbound approach was significant to $95 \%$ confidence. None of the speed differences were significant at $95 \%$ confidence for the $10 \mathrm{mph}$ threshold, although the westbound approach with the speed trailer condition is significant with $90 \%$ confidence.

\subsection{Survey Results}

\section{Mode Choice}

The largest proportion of students $-42.7 \%$ - reported that they most often take the bus to get to school. The next most popular mode choice for students was personal vehicle: $20.28 \%$ of students reported that they drive themselves, and $22.94 \%$ said an adult family member drives them. $9.37 \%$ of students reported carpooling to school: $7.83 \%$ carpooled with another student while $1.54 \%$ said that they carpool with an adult who works near the school. Only $4.71 \%$ of students reported that they most frequently walk or take any other means of transport to get to school. Overall, bus and vehicle travel heavily dominate school travel mode choice according to students. These responses are demonstrated below in Figure 4-15. 


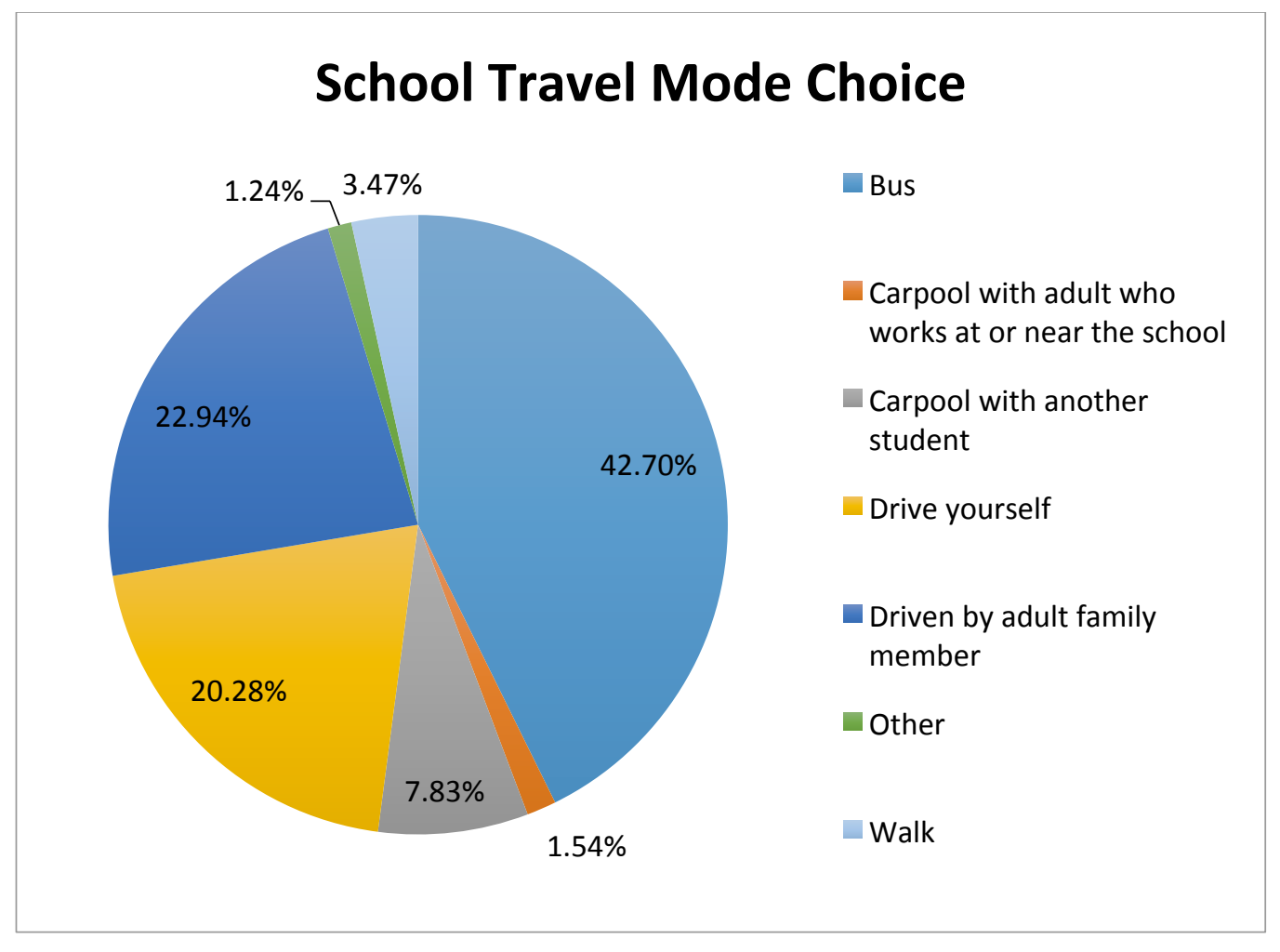

Figure 4-15: Overall mode choice of students

Each school surveyed represents a different type of school location: urban, suburban and rural. The schools also have different enrollment numbers. For these reasons, the responses from each school were separated. The student responses by school are separated below in Figure 4-16. Students from Clay Battelle High School (CBHS), the rural school location, rely more on the school busses and driving themselves than students from the other schools. $56 \%$ of CBHS students say that they usually take the bus, and $22.46 \%$ drive themselves. This is likely because of the location of the school. Because it is isolated, students' homes and their parents' jobs are generally farther away from the school than in the suburban and urban locations of University High School (UHS) and Morgantown High School (MHS). For MHS, 27.4\% of students report that they are most often driven to school by an adult in their family compared to only $13.37 \%$ of CBHS students. Attending a school in an urban location often means that home is closer to 
school and that a students' parent or guardian's work is closer to the school. This would make it easier for adult family members to drive their children to school.

Furthermore, a larger proportion of students from Morgantown High reported that they walk to school. $6.19 \%$ of MHS students reported walking to school, compared to $0.11 \%$ and $1.07 \%$ for UHS and CBHS respectively. Again, urban schools can be located centrally and still be near students' homes. Students who live closer to school are more likely to be willing and able to walk to school. Conversely, rural and suburban school locations, in order to serve students from a wider range of areas, are often located further from students' homes. Longer distances discourage and even prohibit students from walking to school.

\begin{tabular}{|l|r|r|r|r|r|r|r|}
\hline $\begin{array}{l}\text { Mode } \\
\text { Choice }\end{array}$ & Bus & $\begin{array}{l}\text { Carpool } \\
\text { with } \\
\text { adult }\end{array}$ & $\begin{array}{l}\text { Carpool } \\
\text { with } \\
\text { another } \\
\text { student }\end{array}$ & $\begin{array}{l}\text { Drive } \\
\text { themselves }\end{array}$ & $\begin{array}{l}\text { Driven } \\
\text { by adult } \\
\text { family } \\
\text { member }\end{array}$ & Walk & Other \\
\hline CBHS & $56.15 \%$ & $1.07 \%$ & $5.35 \%$ & $22.46 \%$ & $13.37 \%$ & $1.07 \%$ & $0.53 \%$ \\
\hline UHS & $49.27 \%$ & $1.69 \%$ & $7.65 \%$ & $21.71 \%$ & $18.56 \%$ & $0.11 \%$ & $1.01 \%$ \\
\hline MHS & $36.08 \%$ & $1.51 \%$ & $8.33 \%$ & $18.95 \%$ & $27.44 \%$ & $6.19 \%$ & $1.51 \%$ \\
\hline Total & $\mathbf{4 2 . 7 0 \%}$ & $\mathbf{1 . 5 4 \%}$ & $\mathbf{7 . 8 3 \%}$ & $\mathbf{2 0 . 2 8 \%}$ & $\mathbf{2 2 . 9 4 \%}$ & $\mathbf{3 . 4 7 \%}$ & $\mathbf{1 . 2 4 \%}$ \\
\hline
\end{tabular}

Figure 4-16: Student mode choice by school

\section{School Zone Speed Limit Understanding}

The survey included one question to students in attempts to gauge their understanding of the school zone speed limit regulations at their school. They were asked to choose from a list of options their school zone speed limit, or acknowledge that they did not know. The responses, shown in Table 4-18, that very few students were unsure, and that the vast majority knew the school zone speed limit is $15 \mathrm{mph}$. It is possible that students simply chose the slowest value, but given the survey as it was administered, it is assumed that answers reflect a strong understanding of the school zone speed limit. 


\begin{tabular}{|l|r|r|r|r|}
\cline { 2 - 5 } \multicolumn{1}{c|}{} & \multicolumn{4}{c|}{ School Zone Speed Limit Student Responses } \\
\hline School & Total & Morgantown & University & $\begin{array}{l}\text { Clay } \\
\text { Battelle }\end{array}$ \\
\hline $15 \mathrm{mph}$ & $80 \%$ & $80 \%$ & $80 \%$ & $89 \%$ \\
\hline $20 \mathrm{mph}$ & $7 \%$ & $7 \%$ & $7 \%$ & $3 \%$ \\
\hline $25 \mathrm{mph}$ & $5 \%$ & $6 \%$ & $4 \%$ & $3 \%$ \\
\hline $30 \mathrm{mph}$ & $1 \%$ & $0 \%$ & $1 \%$ & $1 \%$ \\
\hline $35 \mathrm{mph}$ & $1 \%$ & $1 \%$ & $1 \%$ & $1 \%$ \\
\hline $\begin{array}{l}\text { Something } \\
\text { else }\end{array}$ & $1 \%$ & $1 \%$ & $1 \%$ & $1 \%$ \\
\hline Not sure & $5 \%$ & $4 \%$ & $7 \%$ & $3 \%$ \\
\hline
\end{tabular}

Overall, most students knew that the school zone speed limit is $15 \mathrm{mph}$ at their school. Eighty percent of students across the district answered correctly when asked what their school's speed limit was. At Clay Battelle, however, $89 \%$ of students answered correctly. This is likely a due to the speed trailers installed at that school site. (Due to delays in conducting the survey) The trailers were installed before the survey was conducted, and likely made students more aware of the speed limit and vehicle speeds in their school zone.

\section{Distracted Driving Responses}

Figure 4-17 shows student responses to the statement that distracted driving is a problem in and around their school zone. Responses varied from school to school. Students from CBHS and UHS, the rural and suburban school locations, most often indicated that they did not have a strong opinion either way regarding the prevalence of distracted driving in their school zones. $31 \%$ of CBHS students and $25 \%$ of UHS students neither agreed nor disagreed with the statement. This could indicate that distracted driving is not an issue that these students feel strongly about, or it could indicate a lack of understanding of what constitutes distracted driving and why it is a concern. The most common response from students at MHS, accounting for 30\% of responses, was strong disagreement that distracted driving is a problem. Students in the 
suburban and rural school zone locations appear to be more concerned about distracted drivers in their school zones.

Average response values, shown in Table 4-19, reflect similarly ambiguous student opinions on distracted driving in their school zones. All average values were very near 4, indicating no preference either way. Despite $30 \%$ of MHS students reporting that they feel strongly that distracted driving is not a problem, the average response was still neutral.

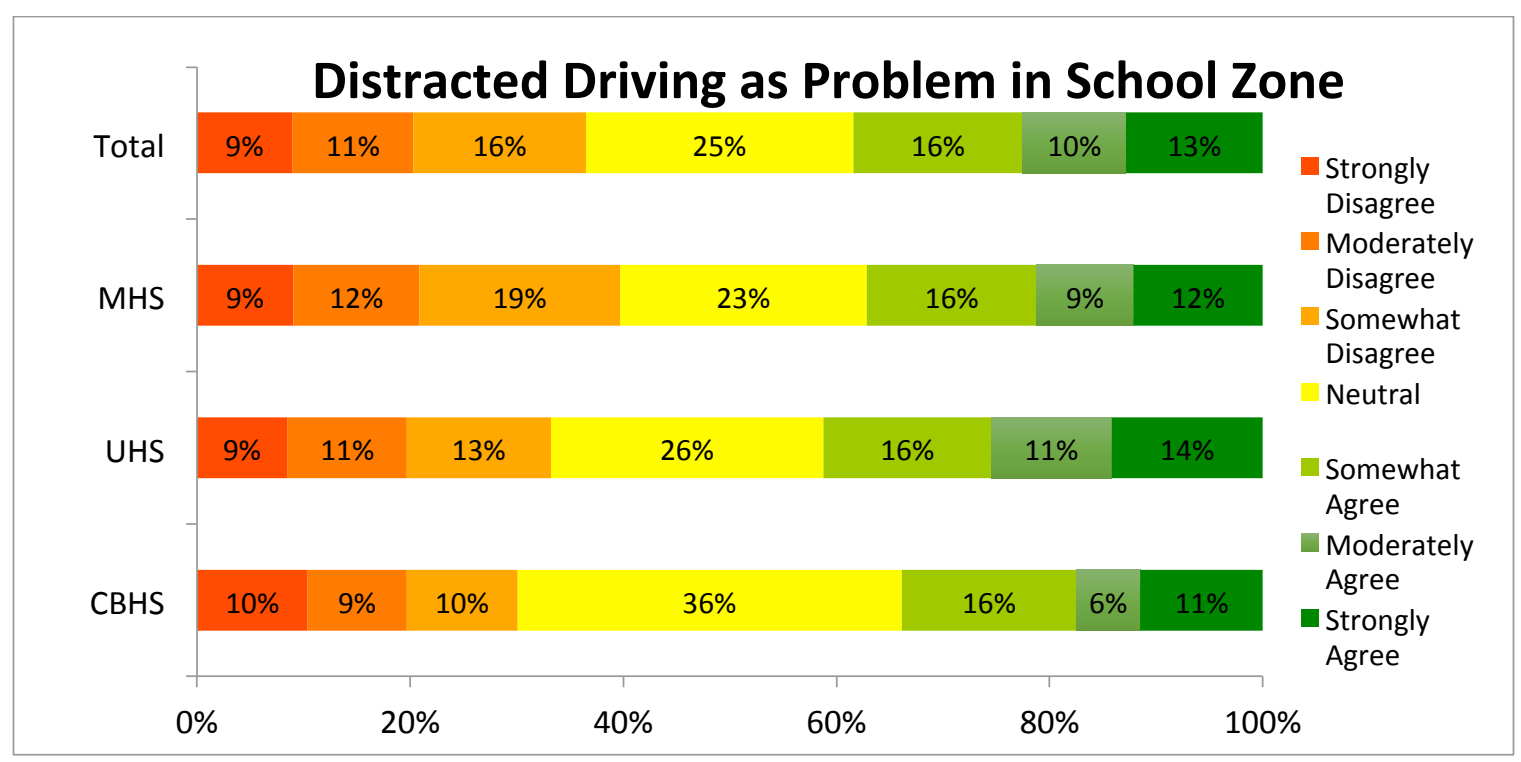

Figure 4-17: Student responses to the statement that distracted driving is a problem in and around their school zone

\begin{tabular}{|l|r|}
\cline { 2 - 2 } \multicolumn{1}{c|}{} & \multicolumn{2}{|l|}{$\begin{array}{l}\text { Distracted Driving } \\
\text { As Problem }\end{array}$} \\
\hline CBHS & 4.027 \\
\hline UHS & 4.195 \\
\hline MHS & 4.009 \\
\hline Overall & 4.080 \\
\hline
\end{tabular}

Table 4-19: Average student responses regarding distracted driving by location

\section{Speeding Responses}

Students taking the survey were asked two questions relating to vehicle speeds. First, they were asked to indicate to what degree they agree to the statement that their school zone speed limit is too slow. Given that most students know what the speed limit in their school zone 
is, it can be assumed that most of the responses to this question are opinions on the actual speed limit and not on their perceived speed limit. That being said, the overall responses indicate that most students do not feel that their school zone speed limit is too slow. $54 \%$ of overall respondents expressed some level of disagreement with the statement. $60 \%$ of MHS students, $47 \%$ of UHS students and $36 \%$ of CBHS students indicated that they do not feel their school zone speed limit is too slow. This trend suggests that location of the school may impact students' opinions of the school zone speed limit. More rural locations, further from cities and closer to highways, may be less appropriate for the required $15 \mathrm{mph}$ speed limit.

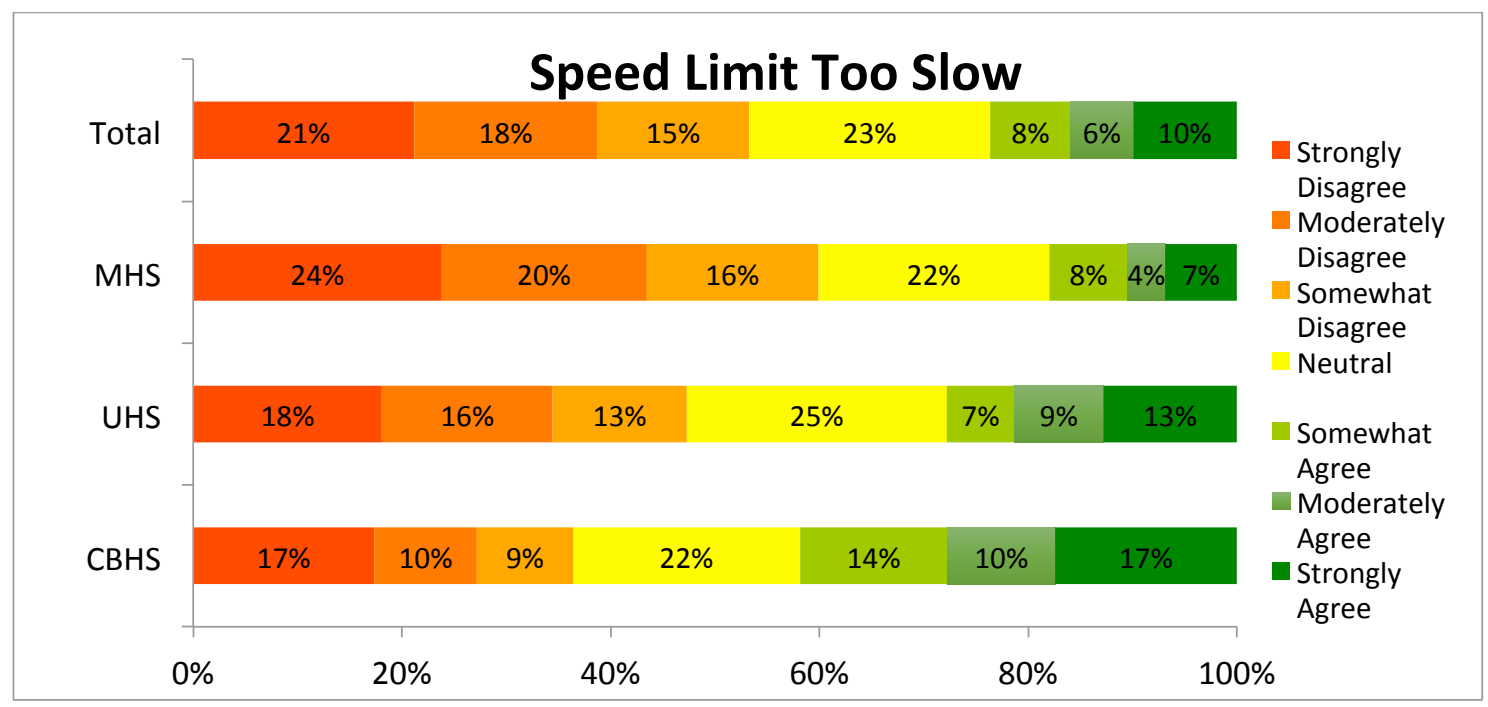

Figure 4-18: Student agreement with the statement "The speed limit is too slow in my school zone" 
Students were also asked if they feel that speeding is a problem in their school zone. A similar trend is apparent in student responses across school locations. 17\% of CBHS students, $12 \%$ of UHS students and $8 \%$ of MHS students indicated that they agree strongly with the statement that speeding is a problem in their school zone. Students in more rural locations more frequently responded that speeding was a problem.

This is reflected by the average response values shown in Table 4-20. While the overall average responses were 3.715 and 3.363, suggesting disagreement that speeding is a problem and speed limits are too slow, the average values for the rural school were much higher: 4.144 and 4.06 respectively. Students at Clay Battelle were more likely to feel that speeding was a concern and that their school zone speed limit was too slow. The UHS average responses were inbetween, at 3.809 and 3.62 respectively. The MHS responses drove the average overall down as the student body at that school was largest.

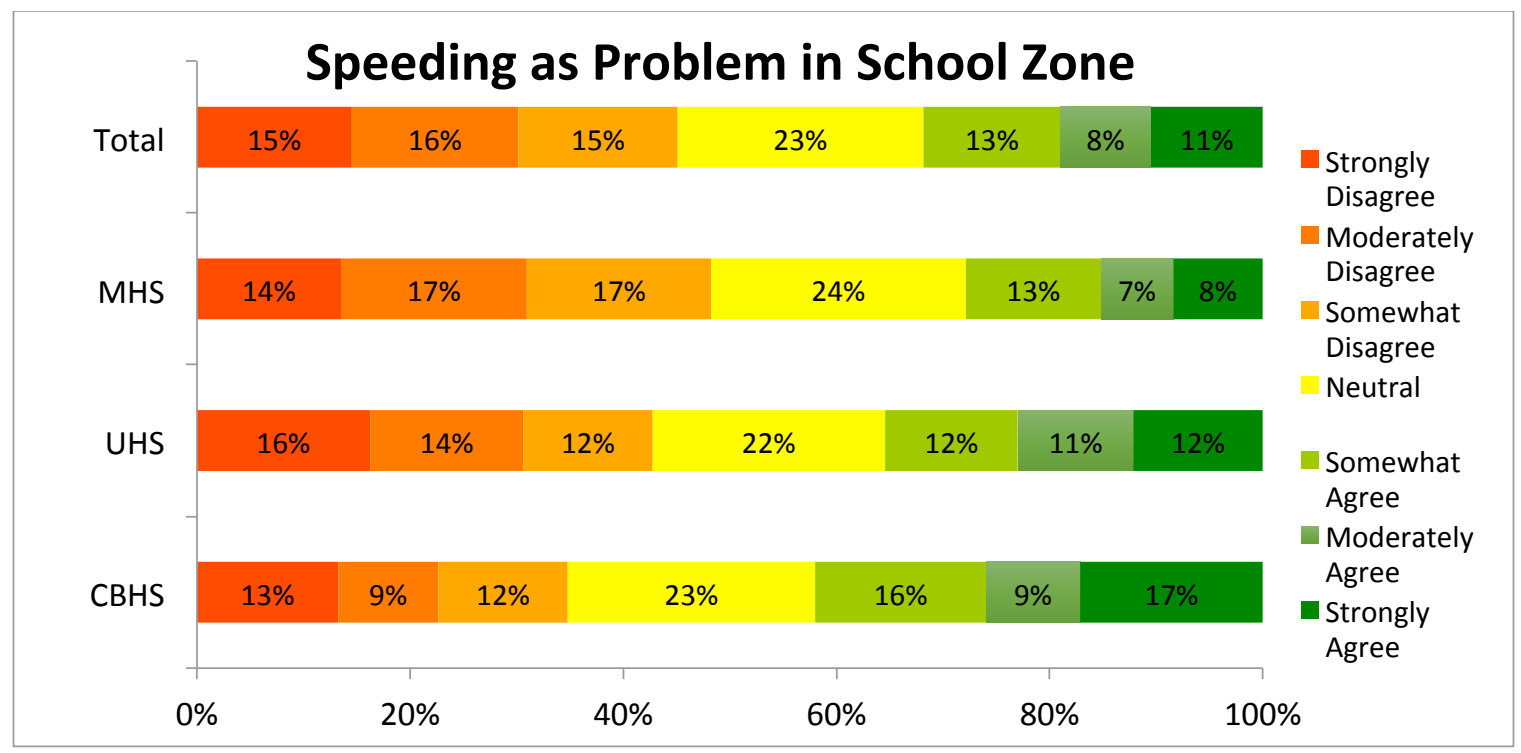

Figure 4-19: Student agreement with the statement "speeding is a problem in my school zone" 


\begin{tabular}{|l|r|r|}
\cline { 2 - 3 } \multicolumn{1}{c|}{} & $\begin{array}{l}\text { Speeding is } \\
\text { Problem }\end{array}$ & $\begin{array}{l}\text { Speed Limit } \\
\text { Too Slow }\end{array}$ \\
\hline CBHS & 4.144 & 4.060 \\
\hline UHS & 3.809 & 3.620 \\
\hline MHS & 3.587 & 3.081 \\
\hline Overall & 3.715 & 3.363 \\
\hline
\end{tabular}

Table 4-20: Average student responses regarding speeding by school location

\section{Safety Perceptions}

Students were asked to assess the safety of their school zone. Two questions were posed: one regarding safety for vehicles and the other for pedestrian safety. Their responses are shown below in Figure 4-20 and Figure 4-21. Because each school zone is different, responses were considered both aggregated across the district and separated by school. There were no striking imbalances in responses, with a fairly wide range of opinions for both pedestrian and vehicle safety at all schools. Responses were also fairly consistent across schools. Generally, students' assessment of safety was neutral skewed towards positive. $58 \%$ of students reported at least slight agreement to the statement that vehicles are safe in their school zone, and 55\% reported slight agreement to the same statement for pedestrian safety in their school zone. Only $21 \%$ of students across the surveyed schools reported some level of perceived danger for vehicles and $25 \%$ reported perceived danger for pedestrians. The wide variation of these answers could represent a lack of interest in or awareness of school travel safety problems. 


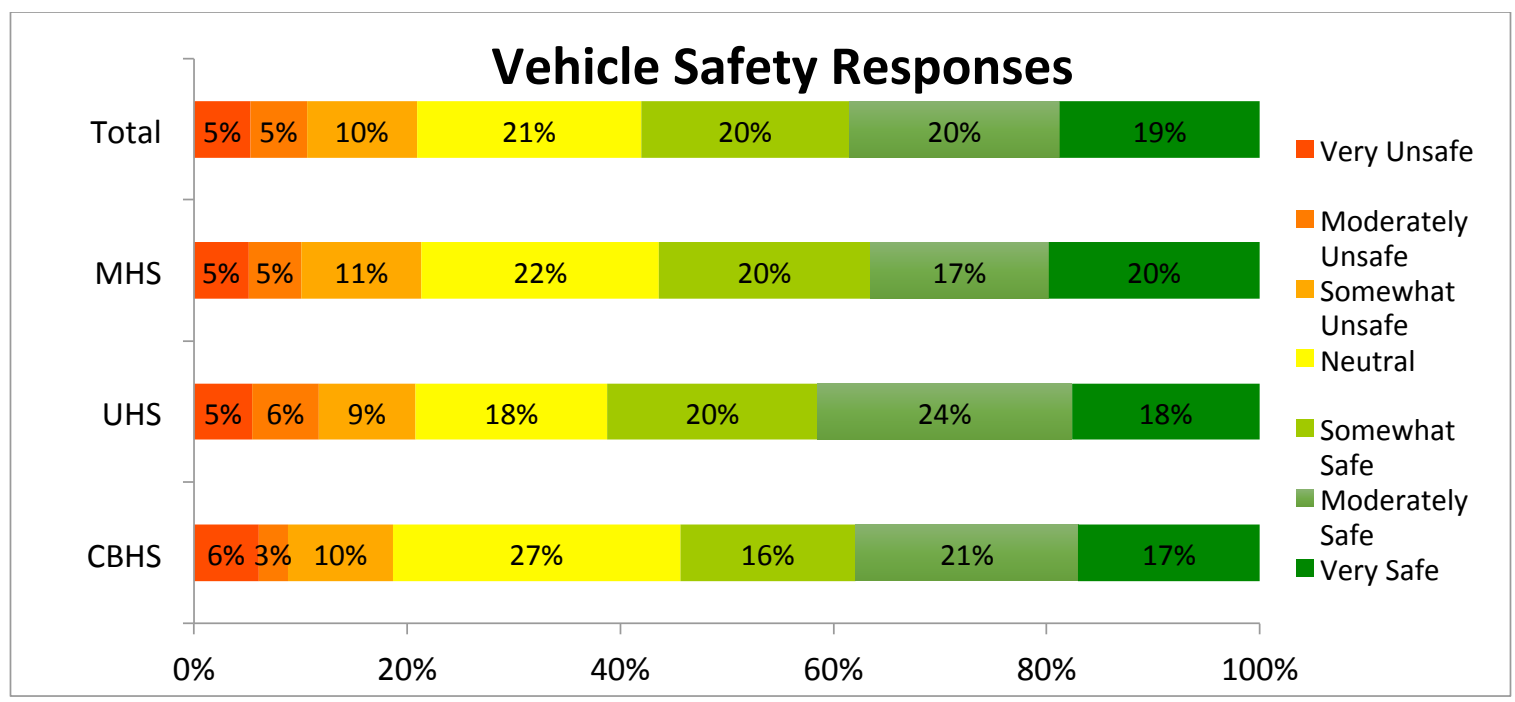

Figure 4-20: Student perception of their school zone safety for vehicles

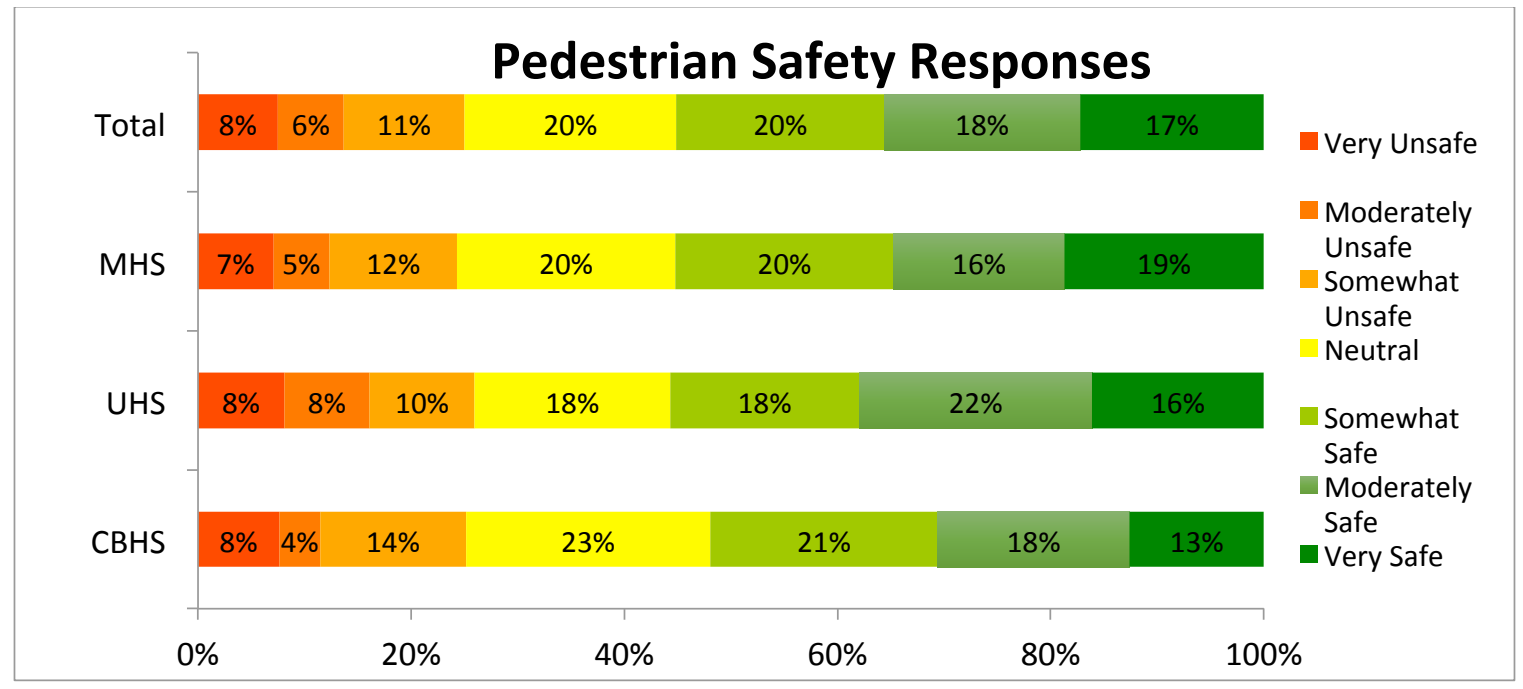

Figure 4-21: Student perception of their school zone safety for pedestrians

Students were also asked to evaluate the clarity of traffic signs in and around their school zone. Student responses are shown below in Figure 4-22. Their overall evaluation of sign clarity was largely similar to their evaluation of safety in that it was generally neutral skewed positive. Students at University High felt that their signs were particularly clear, however, as $72 \%$ of them reported at least somewhat clear signs (with 32\% reporting very clear signage) compared to $55 \%$ from MHS and $68 \%$ from CBHS (with only $21 \%$ and $22 \%$ reporting very clear signage respectively). Based on values shown in Table 4-21, the average response at University High was 
5.325 as compared to 5.071 and 4.807 for CBHS and MHS respectively. A closer look at the particular signage at each site could potentially offer insight as to what signage practices students consider clear, and which could use improvements.

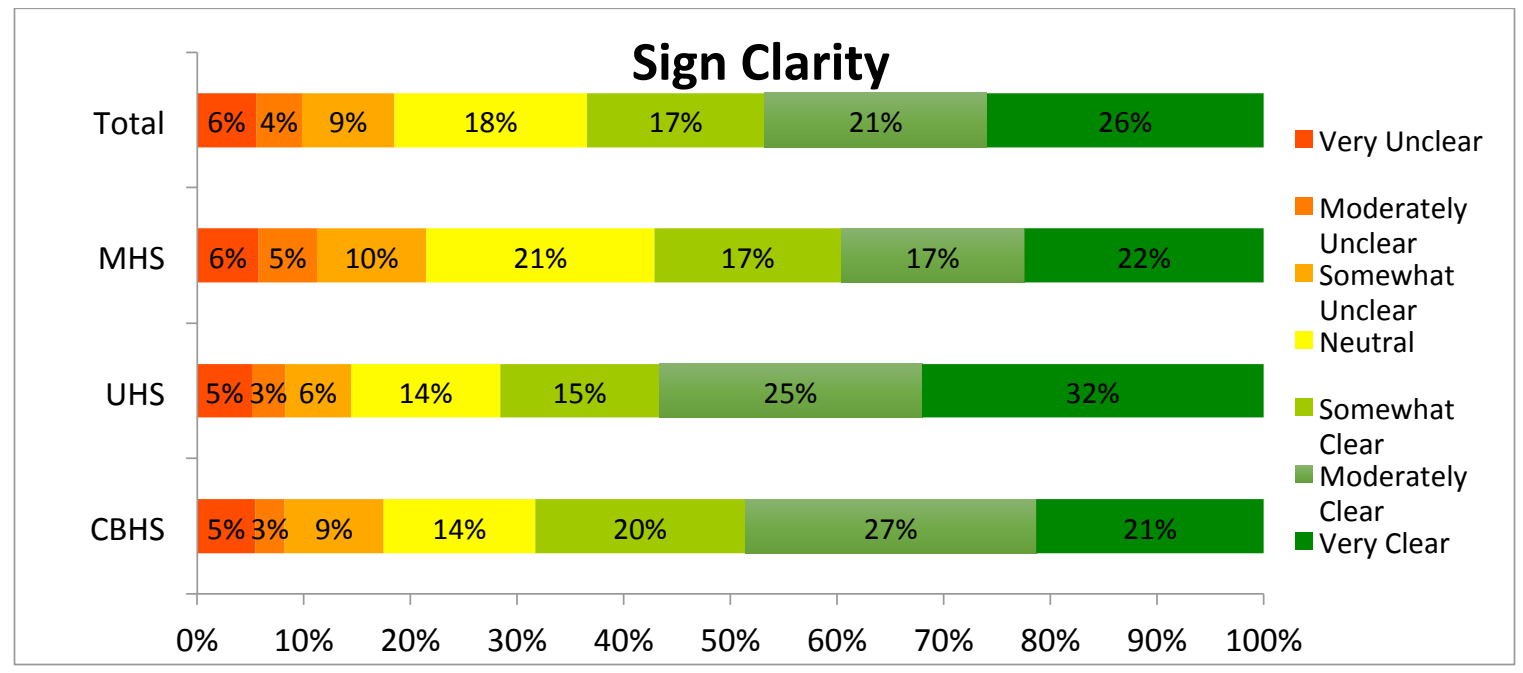

Figure 4-22: Student perception of clarity of traffic signs in and around their school zone

\begin{tabular}{|l|r|r|r|}
\cline { 2 - 4 } \multicolumn{1}{c|}{} & \multicolumn{1}{l|}{ Vehicles } & Pedestrians & \multicolumn{1}{l|}{ Signage } \\
\hline CBHS & 4.758 & 4.508 & 5.071 \\
\hline UHS & 4.824 & 4.596 & 5.325 \\
\hline MHS & 4.762 & 4.649 & 4.807 \\
\hline Overall & 4.785 & 4.617 & 5.023 \\
\hline
\end{tabular}

Table 4-21: Average safety perception responses by school location

\subsection{Summary of Results}

The speed study demonstrated that speed trailers (and similar devices) can be effective for lowering vehicle speeds through school zones. The average vehicle speeds entering the study site dropped $10.13 \mathrm{mph}$ in the presence of the speed trailers. A $10 \mathrm{mph}$ change was significant with $90 \%$ confidence. The speed reductions were also significant exiting the school zone from the other approach, suggesting that the speed reductions are at least partially maintained while vehicles travel through the school zone. While afternoon speeds were on average slightly faster than morning speeds, the differences were generally slight enough to not have any practical significance. 
Compliance with the school zone speed limit was very low across all conditions, but the presence of the speed trailer did greatly improve the likelihood of traveling within $5 \mathrm{mph}$ of the speed limit for all conditions. The low compliance rates are likely a function of the school site. Along WV-7, a highway with speed limits as high as $55 \mathrm{mph}$, the school zone speed limit of 15 mph for such a short stretch is difficult to enforce when compliance is so low.

The student surveys provided a number of valuable insights related to school travel in West Virginia. Regarding mode choice, most students rely on the bus to get to school. This is particularly true for the more rural school locations. Very few students (roughly $8 \%$ of those surveyed) rely on carpooling to get to school, and even fewer walk or bike (less than $4 \%$ ). Personal vehicle trips, split between riding with a parent and driving themselves, make up the remainder of school trips, accounting for roughly $40 \%$. Students in more rural locations reported driving themselves more often, whereas the students of the urban school reported more often that an adult family member drove them.

Despite a surprisingly consistent knowlege of the school zone speed limits, students vastly underestimated school zone speeding. While $80 \%$ of students knew that the school zone speed limit is $15 \mathrm{mph}$, only $32 \%$ reported that speeding is a problem in their school zone. The speed study for Clay Battelle shows that compliance with speeds $5 \mathrm{mph}$ above the actual limit is drastically lower than this would suggest. These responses could mean that students understand what school zone speeds should be, but exaggerate the degree to which they or the person who drives them to school follow these speeds. It could also reflect that poor speed limit compliance does not concern many students. Some students did still report that speeding is a problem in their school zone, particularly in the rural school where $17 \%$ of student respondents felt strongly that speeding was a problem. The responses to the questions regarding vehicle and pedestrian safety 
in the school zones were consistently positive, with over $50 \%$ of respondents at each school reporting safe travel for pedestrians and vehicles.

\section{Conclusions \& Recommendations}

\subsection{Conclusions}

A review of the literature revealed that speeding was a major concern related to school zone safety, particularly in rural school zones adjacent to high-speed roadways. Traffic control devices are frequently employed in school zones in hopes of reducing speeding, and improving speed limit compliance. Speed monitoring displays, which provide immediate feedback to drivers, are a particularly effective means of alerting drivers of their speeding and thus influencing their driving behavior. This study has confirmed that signs that offer speed feedback to drivers can be effective in reducing vehicle speeds in rural school zones. Despite continued low compliance with school zone speed limits, the feedback did alert drivers of their high speeds, reducing the average speeds throughout the school zone while children were present.

In surveying students, important trends were observed, particularly when looking at responses from different school locations. Students from a rural location, for example, get to school differently than students in an urban location. They rely on busses and driving themselves more while urban students are driven by adults and can even walk more frequently. They have different perceptions of speeding near their schools, and different views related to safety in their school zones. This is, put simply, because these schools are different. Their locations and travel safety perceptions set them apart. 


\subsection{Recommendations}

Because schools in West Virginia are so different from each other, their school zone design and regulation should be considered on a case-by-case basis. While a $15 \mathrm{mph}$ school zone speed limit may be appropriate in an urban or suburban school zone environment, it may not be appropriate near or along a highway. Compliance with the school zone speed limit in the case observed in this study was exceedingly low. It could be said that drivers largely ignored the prescribed $15 \mathrm{mph}$ speed limit. A one-size-fits-all approach to school zone regulations is impractical, and potentially unsafe. With the majority of drivers exceeding the school zone speed limit at a rural school along a highway by more than $5 \mathrm{mph}$, a vehicle that slows dramatically to obey the speed limit could cause rear-end collisions. It is true that vehicle speeds correspond to pedestrian-vehicle collision severity, but that does not mean that the school zone speed limit needs to be as low as possible. Along high-speed roads and highways, schools such as the one studied are not readily accessible by foot. This fact is corroborated the survey data which shows that very few, even less than one percent in some cases, of students report that they walk to school in these cases. In such circumstances, the required 15 mph speed limit may not be necessary. West Virginia has so many different types of schools with diverse travel conditions for students, it may be worth considering broadening school zone legislation to allow more specialization. Allowing local communities, governments and transportation professionals more freedom to decide how their school zones should be regulated, in terms of speed, signing and traffic control, could lead to more appropriate and realistic measures being put in place.

Overall, speed monitoring displays are a valuable traffic control tool that can and should be implemented in school zones where speeding is of particular concern. Because every school location is unique, and because speed monitoring displays are relatively expensive in comparison 
to other traffic control devices, they should not be used without consideration of the circumstances specific to any given school zone. While they have proven effective in reducing vehicle travel speeds, SMDs may not be appropriate for implementation in all school zones. They will not solve congestion problems or prevent driver distraction. SMD implementation should be just a part of a wider, concerted effort to continue to improve traffic safety near schools.

\subsection{Future Research}

In order to gain a more comprehensive picture of the effects of speed monitoring displays on school travel safety, a series of studies similar to this one could be conducted at various school sites (rural, suburban and urban) and survey a wider range of people impacted by school travel to validate the conclusions of this study. Future studies may hope to capture public perception of the traffic control devices tested with additional surveys at the sites where traffic controls are tested. This would provide a more robust picture of the various conditions at different types of schools, and provide a clearer framework for traffic control implementation in schools zones and surrounding roads. A longer study could also offer insights as to the long-term effectiveness of various traffic control measures. 


\section{References}

AASHTO. (2011). Policy on geometric design of highways and streets. American Association of State Highway and Transportation Officials, Washington, DC, 1(990), 158.

Anderson, R. W. G., McLean, A. J., Farmer, M. J. B., Lee, B. H., \& Brooks, C. G. (1997). Vehicle travel speeds and the incidence of fatal pedestrian crashes. Accident Analysis \& Prevention, 29(5), 667-674.

Barton, B. K., \& Schwebel, D. C. (2007). The roles of age, gender, inhibitory control, and parental supervision in children's pedestrian safety. Journal of Pediatric Psychology, 32(5), 517-526.

Braza, M., Shoemaker, W., \& Seeley, A. (2004). Neighborhood design and rates of walking and biking to elementary school in 34 California communities. American journal of health promotion, 19(2), 128-136.

Bunn, F., Collier, T., Frost, C., Ker, K., Roberts, I., \& Wentz, R. (2003). Traffic calming for the prevention of road traffic injuries: systematic review and meta-analysis. Injury prevention, 9(3), 200-204.

DeYoung, A. J., \& Howley, C. B. (1990). The political economy of rural school consolidation. Peabody Journal of Education, 67(4), 63-89.

DiGuiseppi, C., Li, L., \& Roberts, I. (1998). Influence of travel patterns on mortality from injury among teenagers in england and wales, 1985-95: Trend analysis. BMJ: British Medical Journal, 316(7135), 904-905.

Distracted Driving : State Laws. (2016). Distraction.gov. Retrieved 12 March 2016, from http://www.distraction.gov/stats-research-laws/state-laws.html

Ewing, R., Schroeer, W., \& Greene, W. (2004). School location and student travel analysis of factors affecting mode choice. Transportation Research Record: Journal of the Transportation Research Board, (1895), 55-63.

Gårder, P. E. (2004). The impact of speed and other variables on pedestrian safety in Maine. Accident Analysis \& Prevention, 36(4), 533-542.

GHSA. (2016). Distracted Driving Laws. State Distracted Driving Laws. Governor's Highway Safety Association, Mar. 2016.

Grabowski, J.G., Goodman, S., (2009). Distracted Drivers in School Zones: A National Report. Safe Kids USA.

Gregory, B., Irwin, J. D., Faulks, I. J., \& Chekaluk, E. (2014). Speeding in school zones: Violation or lapse in prospective memory? Journal of Experimental Psychology. Applied, 20(3), 191-198. 
Hamric, K., Martinelli, D. R., Unnikrishnan, A., \& Martinelli, D. (2013). An Evaluation of School Zone Traffic Control Strategies, Phase I (No. MAUTC-2010-02).

Harbluk, J. L., Noy, Y. I., Trbovich, P. L., \& Eizenman, M. (2007). An on-road assessment of cognitive distraction: Impacts on drivers' visual behavior and braking performance. Accident Analysis \& Prevention, 39(2), 372-379.

Harborview Injury Prevention and Research Center. (1997). training programs [On-line]. Available: http:// depts.washington.edu/hiprc/childinjury.

Harre, N. (2003). Discrepancy between actual and estimated speeds of drivers in the presence of child pedestrians. Injury Prevention, 9(1), pp 38-41.

Harris County Justice Courts. (2008). Fines for speeding tickets. Retrieved 12 March 2016 from http://www.jp.hctx.net/traffic/Fines.pdf

Holland, D. W., \& Baritelle, J. L. (1975). School consolidation in sparsely populated rural areas: A separable programming approach. American Journal of Agricultural Economics, 57(4), 567-575.

Isebrands, Hillary N., and Shauna L. Hallmark. (2007). "School Zone Safety and Operational Problems at Existing Elementary Schools." Institute of Transportation Engineers.ITE Journal 77.3(2007): 26-31. ProQuest. Web. 6 Mar. 2016.

Killeen, K., \& Sipple, J. (2000). School consolidation and transportation policy: An empirical and institutional analysis. Arlington, VA: Rural School and Community Trust.

Klauer, S. G., Guo, F., Simons-Morton, B. G., Ouimet, M. C., Lee, S. E., \& Dingus, T. A. (2014). Distracted driving and risk of road crashes among novice and experienced drivers. New England journal of medicine, 370(1), 54-59.

Lee, Choulki; Lee, Sangsoo; Choi, Bongsoo; Oh, Youngtae. (2006). Effectiveness of speedmonitoring displays in speed reduction in school zones. Transportation Research Record:Journal of the Transportation Research Board, No. 1973, pp 27 - 35.

Lewis-Evans, B., \& Charlton, S. G. (2006). Explicit and implicit processes in behavioural adaptation to road width. Accident Analysis \& Prevention, 38(3), 610-617.

McComas, J., MacKay, M., \& Pivik, J. (2002). Effectiveness of virtual reality for teaching pedestrian safety. CyberPsychology \& Behavior, 5(3), 185-190.

McCoy, Patrick T.; Mohaddes, Abbas K.; Haden, Richard. (1981). Effectiveness of school speeds and their enforcement. Transportation Research Record: Journal of the Transportation Research Board, No. 811, pp 1-7.

McDonald, N. C. (2008). Household interactions and children's school travel: the effect of parental work patterns on walking and biking to school. Journal of transport geography, 16(5), 324-331. 
McDonald, N. C., Brown, A. L., Marchetti, L. M., \& Pedroso, M. S. (2011). US school travel, 2009: an assessment of trends. American journal of preventive medicine, 41(2), 146-151.

National Highway Traffic Safety Administration. (2002). Traffic Safety Fact 2001: A Compilation of Motor Vehicle Crash Data from the Fatality Analysis Reporting System and the General Estimates System. Report No. DOT HS 809 484. National Center for Statistics and Analysis, US Department of Transportation, Washington, DC.

National Highway Traffic Safety Administration. (2004). Safe Routes to School: Practice and Promise (DOT-HS-809-742). US Government Printing Office, Washington, DC

National Research Council (US). Committee on School Transportation Safety. (2002). The Relative Risks of School Travel: A National Perspective and Guidance for Local Community Risk Assessment (No. 269). National Academies Press.

O’Brien, Sarah; Simpson, Carrie. (2011). Use of 'your speed' changeable message signs n school zones: experience from North Carolina safe routes to school program. Transportation Research Record: Journal of the Transportation Research Board, No. 2318, pp 128-134.

Rain Measurement Guide. (2013). Weather Insurance Agency. Retrieved 7 December 2015, from http://www.weatherins.com/PDFs/WIARainMeasurementGuide.pdf

Rakauskas, M. E., Gugerty, L. J., \& Ward, N. J. (2004). Effects of naturalistic cell phone conversations on driving performance. Journal of safety research, 35(4), 453-464.

Ratanavaraha, Vatanavongs; Watthanaklang, Duangdao. (2013). The Effectiveness of Temporary Traffic Calming Devices on Reducing Speeds of Traffic Flow in School Zones. Indian Journal of Science and Technology, 6(5).

Rohlich, Nina, Peter Haas, and Frances Edwards. "Exploring the Effectiveness of Transit Security Awareness Campaigns in the San Francisco Bay Area, California." Transportation Research Record: Journal of the Transportation Research Board 2146 (2010): 92-99.

Rosenbloom, Tova; Haviv, Matan; Peleg, Ariela; Nemrodov, Dan. (2008). The effectiveness of road-safety crossing guards: Knowledge and behavioral intentions. Safety Science. 46(10), pp 1450-1458.

Rundmo, Torbjorn; Iversen, Hilde. (2004). Risk perception and driving behaviour among adolescents in two Norwegian counties before and after a traffic safety campaign. Safety Science, 42(1), pp 1-21.

Saibel, C., Salzberg, P., Doane, R., \& Moffat, J. (1999). Vehicle speeds in school zones. Institute of Transportation Engineers. ITE Journal, 69(11), 38.

Schlossberg, M., Greene, J., Phillips, P. P., Johnson, B., \& Parker, B. (2006). School trips: effects of urban form and distance on travel mode. Journal of the American Planning Association, 72(3), 337-346. 
Schrader, Michael. (1999). Study of effectiveness of selected school zone traffic control devices. Transportation Research Record: Journal of the Transportation Research Board, No. 1692, pp 24-36.

Shults, R. A., Olsen, E., \& Williams, A. F. (2015). Driving among high school students-United States, 2013. MMWR: Morbidity and mortality weekly report, 64, 313-317.

Steinberg, L. (2008). A social neuroscience perspective on adolescent risk-taking. Developmental review, 28(1), 78-106.

SWMPC | Traffic counts. (2015). Swmpc.org. Retrieved 23 March 2016, from http://www.swmpc.org/traffic_counts.asp

Taylor, David; Tight, Miles. (1997). Public attitudes and consultation in traffic calming schemes. Transport Policy. 4(3), pp 171-182.

Texas Driving University. (2012). Texas school zones. Retrieved 12 March 2016 from http://texas.drivinguniversity.com/driving-safety/texas-school-zones/

TRB. (2002). Relative risks of school travel: A national perspective and guidance for local community risk assessment -- special report 269

Trinkaus, J. (1996). Compliance with a school zone speed limit: An informal look. Perceptual and motor skills, 82(2), 433-434.

Trinkaus, J. (1998). Compliance with a school zone speed limit: Another look. Perceptual and motor skills, 87(2), 673-674.

Ulleberg, Pal. (2001). Personality subtypes of young drivers. relationship to risk-taking preferences, accident involvement, and response to a traffic safety campaign. Transportation Research Part F: Psychology and Behaviour. 4(4).

Van Wagner, M., Van Houten, R., \& Betts, B. (2011). The effects of a rectangular rapid-flashing beacon on vehicle speeds. Journal of Applied Behavior Analysis, 44(3), pp 629-633.

Warsh, J., Rothman, L., Slater, M., Steverango, C., \& Howard, A. (2009). Are school zones effective? An examination of motor vehicle versus child pedestrian crashes near schools. Injury Prevention, 15(4), 226-229.

West Virginia Legislature. "Traffic Regulations and Laws of the Code." West Virginia Code. Chapter 17C. 2014.

Whitebread, D., \& Neilson, K. (2000). The contribution of visual search strategies to the development of pedestrian skill by 4-11 year-old children. British Journal of Educational Psychology, 70, 539-557.

Williams, A. F. (2003). Teenage drivers: patterns of risk. Journal of safety research, 34(1), 5-15. 
Wills, K. E., Christoffel, K. K., Lavigne, J. V., Tanz, R. R., Schofer, J. L., Donovan, M., \& Kalangis, K. (1997). Patterns and correlates of supervision in child pedestrian injury. Journal of Pediatric Psychology, 22(1), 89-104.

Wilson, F. A., \& Stimpson, J. P. (2010). Trends in fatalities from distracted driving in the United States, 1999 to 2008. American journal of public health, 100(11), 2213-2219.

Wooldridge, M. D., Cooner, S. A., \& Fitzpatrick, K. (2003). Transportation concerns near schools. In 2nd Urban Street Symposium: Uptown, Downtown, or Small Town: Designing Urban Streets That Work.

Yeaton, W. H., \& Bailey, J. S. (1978). Teaching Pedestrian Safety Skills to Young Children: an Analysis and One-Year Follow up. Journal of Applied Behavior Analysis, 11(3), 315329.

Young, E. J., Dixon, K., \& Board, T. R. (2003). The effects of school zones on driver behavior. In 2nd Urban Streets Symposium, Anaheim, California. 
Appendix A: Student Survey Template

1. How do you most often get to school?

Mark only one oval.

Bus

D Dive yourself

Carpool with another student

Carpool with adult who works at or near the school

Driven by adut famly member

Walk

( Other

2. What do you think the speed limit is in your designated achool zone?

Mark only one oval.

15 miles per hour (mph)

$20 \mathrm{mph}$

$25 \mathrm{mph}$

$30 \mathrm{mph}$

$35 \mathrm{mph}$

Something else

Not sure 
Please fill in the circle that best represents your opinion on each of the following statements.

(Select one per row)

\begin{tabular}{|c|c|c|c|c|c|c|c|c|}
\hline & 1 & 2 & 3 & 4 & 5 & 6 & 7 & \multirow[b]{3}{*}{ Strongly Agree } \\
\hline & \multicolumn{7}{|c|}{ Students drive just as safely as sodults. } & \\
\hline \multirow[t]{2}{*}{$\begin{array}{l}\text { Strongly } \\
\text { Disagree }\end{array}$} & 0 & 0 & 0 & $\mathrm{O}$ & $\mathrm{O}$ & O & 0 & \\
\hline & \multicolumn{7}{|c|}{ Your school zone area is safe for vehicles to travel. } & \multirow{3}{*}{ Strongly Agree } \\
\hline \multirow[t]{2}{*}{$\begin{array}{l}\text { Strongly } \\
\text { Disagree }\end{array}$} & 0 & $\mathrm{O}$ & O & $\mathrm{O}$ & $\mathrm{O}$ & 0 & O & \\
\hline & \multicolumn{7}{|c|}{ Your school zone area is safe for pedestrians to travel. } & \\
\hline \multirow[t]{2}{*}{$\begin{array}{l}\text { Strongly } \\
\text { Disagree }\end{array}$} & 0 & $\mathrm{O}$ & $\mathrm{O}$ & $\mathrm{O}$ & $\mathrm{O}$ & $\mathrm{O}$ & 0 & \multirow[t]{2}{*}{ Strongly Agree } \\
\hline & \multicolumn{7}{|c|}{ The traffic signs in and sround your school zone are clear. } & \\
\hline \multirow[t]{2}{*}{$\begin{array}{l}\text { Strongly } \\
\text { Disagree }\end{array}$} & 0 & $\mathrm{O}$ & O & $\mathrm{O}$ & $\mathrm{O}$ & 0 & 0 & \multirow[t]{2}{*}{ Strongly Agree } \\
\hline & \multicolumn{7}{|c|}{ In your opinion, the school zone speed limit is too slow. } & \\
\hline \multirow[t]{2}{*}{$\begin{array}{l}\text { Strongly } \\
\text { Disagree }\end{array}$} & 0 & $\mathrm{O}$ & $\mathrm{O}$ & O & $\mathrm{O}$ & 0 & O & \multirow[t]{2}{*}{ Strongly Agree } \\
\hline & \multicolumn{7}{|c|}{ Speeding is a problem in your school zone. } & \\
\hline \multirow[t]{2}{*}{$\begin{array}{l}\text { Strongly } \\
\text { Disagree }\end{array}$} & $\mathrm{O}$ & $\mathrm{O}$ & $\mathrm{O}$ & $\mathrm{O}$ & $\mathrm{O}$ & 0 & 0 & \multirow[t]{2}{*}{ Strongly Agree } \\
\hline & \multicolumn{7}{|c|}{ Drivers use designated school pick-up snd drop-off locations appropristely. } & \\
\hline \multirow[t]{2}{*}{$\begin{array}{l}\text { Strongly } \\
\text { Disagree }\end{array}$} & 0 & $\mathrm{O}$ & $\mathrm{O}$ & O & $\mathrm{O}$ & 0 & 0 & \multirow[t]{2}{*}{ Strongly Agree } \\
\hline & \multicolumn{7}{|c|}{$\begin{array}{l}\text { Drivers who don't psy full attention to their driving (distracted drivers) are } \\
\qquad \text { a problem in and around your school zone. }\end{array}$} & \\
\hline \multirow[t]{2}{*}{$\begin{array}{l}\text { Strongly } \\
\text { Disagree }\end{array}$} & 0 & 0 & $\mathrm{O}$ & $\mathrm{O}$ & $\mathrm{O}$ & 0 & 0 & \multirow[t]{2}{*}{ Strongly Agree } \\
\hline & \multicolumn{7}{|c|}{$\begin{array}{l}\text { Student drivers with passengers are more likely to be distrocted in and } \\
\text { around school zones. }\end{array}$} & \\
\hline \multirow[t]{2}{*}{$\begin{array}{l}\text { Strongly } \\
\text { Disagree }\end{array}$} & 0 & 0 & 0 & 0 & 0 & 0 & 0 & \multirow[t]{2}{*}{ Strongly Agree } \\
\hline & \multicolumn{7}{|c|}{$\begin{array}{l}\text { There are more traffic problems in snd sround your school zone in the } \\
\text { morning than in the afternoon. }\end{array}$} & \\
\hline \multirow[t]{2}{*}{$\begin{array}{l}\text { Strongly } \\
\text { Disagree }\end{array}$} & 0 & 0 & 0 & $\mathrm{O}$ & $\mathrm{O}$ & 0 & 0 & \multirow[t]{2}{*}{ Strongly Agree } \\
\hline & \multicolumn{7}{|c|}{$\begin{array}{l}\text { The person who drives you to school obeys the speed limit while in and } \\
\text { around the school zone. }\end{array}$} & \\
\hline $\begin{array}{l}\text { Strongly } \\
\text { Disagree }\end{array}$ & 0 & 0 & 0 & $\mathrm{O}$ & 0 & 0 & $\mathrm{O}$ & Strongly Agree \\
\hline
\end{tabular}

